La

Révolution

française

\section{La Révolution française}

Cahiers de l'Institut d'histoire de la Révolution française

$9 \mid 2015$

Citoyenneté, république, démocratie dans la France de la Révolution

\title{
Penser avec le genre : Trouble dans la citoyenneté révolutionnaire
}

Thinking with Gender. New Boundaries of Citizenship during the French Revolution

\section{Guillaume Mazeau et Clyde Plumauzille}

\section{OpenEdition}

Journals

Édition électronique

URL : https://journals.openedition.org//rf/1458

DOI : $10.4000 /$ Irf. 1458

ISSN : 2105-2557

Éditeur

IHMC - Institut d'histoire moderne et contemporaine (UMR 8066)

Référence électronique

Guillaume Mazeau et Clyde Plumauzille, «Penser avec le genre : Trouble dans la citoyenneté révolutionnaire », La Révolution française [En ligne], 9 | 2015, mis en ligne le 16 novembre 2015, consulté le 21 septembre 2021. URL : http://journals.openedition.org//rf/1458 ; DOI : https://doi.org/ $10.4000 /$ Irf. 1458

Ce document a été généré automatiquement le 21 septembre 2021.

(c) La Révolution française 


\title{
Penser avec le genre : Trouble dans la citoyenneté révolutionnaire
}

\author{
Thinking with Gender. New Boundaries of Citizenship during the French \\ Revolution
}

Guillaume Mazeau et Clyde Plumauzille

\section{Sous la Révolution, le genre}

1 Le genre n'est pas seulement une utile catégorie d'analyse pour l'histoire de la Révolution française. Il est une catégorie nécessaire. Tout à la fois concept et grille de lecture, il permet d'historiciser la construction sociale de la différence perçue entre les sexes, mais constitue également, et peut-être surtout, une « façon première de signifier des rapports de pouvoir ${ }^{1}$. En d'autres termes, le genre nous permet de penser la dimension sexuée du pouvoir et des relations de pouvoir durant la crise politique d'exceptionnelle ampleur qu'est la période révolutionnaire. Cette remarque n'est pas déconnectée d'enjeux présents : la Révolution a légué un héritage paradoxal. Son modèle républicain formule la promesse d'une émancipation universelle pour " tous ", tout en excluant de façon durable les femmes de la sphère politique légitime et du droit de suffrage. Il affirme ainsi dans un même mouvement l'abstraction de l'individu et la primauté de la différence des sexes dans la construction de la citoyenneté. Adopter une perspective de genre, analyser ce droit de cité ambigu des femmes pour penser la Révolution, c'est donc à la fois interroger les totems - la citoyenneté, l'égalité et l'universalité des droits - et les tabous l'exclusion, la différence, et les contretemps de l'émancipation - de l'universalisme républicain. Cela revient aussi à démonter les mécanismes complexes de la construction idéologique et pratique de la citoyenneté, dont les contours ne sont ni pensés ni dessinés dès 1789 mais se dilatent ou se rétractent en fonction des situations et des ressources qui se présentent aux acteurs de la période révolutionnaire, contraints d'arbitrer, souvent dans l'urgence et l'incertitude, entre leurs convictions intellectuelles, les rapports de force et les stratégies de survie politique. 
2 Nous défendons dans les lignes qui suivent une conception large et ouverte de la citoyenneté. Souvent réduite à l'existence de droits, à la possession d'un statut juridique ou à l'exercice d'une capacité politique (et plus particulièrement du vote), la citoyenneté gagne à être élargie à l'ensemble des expériences politiques et sociales qui relie les individus à la communauté politique et civique ${ }^{2}$. Saisir les manières dont les femmes et les hommes se sont sentis citoyens, ont agi en tant que citoyens, ont été vus comme citoyens ou exclus de la citoyenneté, suppose de prendre en compte les gestes les plus anodins de la vie ordinaire qui, surtout en période de crise politique, s'adressent en permanence au destin de la Cité. Cette diversité des manières de se penser, de se positionner et d'agir par rapport aux normes instituées de la citoyenneté implique aussi que nous parlerons le plus possible de "citoyennetés" au pluriel, en raison des feuilletages et des strates d'identification et d'engagement qui cohabitent et se juxtaposent au sein des mêmes individus. Surtout, il s'agit ici de voir comment le genre et les citoyennetés interagissent en période de révolution et contribuent à dessiner les contours et les tensions internes de la société politique et civile qui tente de s'inventer, dans la plus grande difficulté, à la fin $\mathrm{du}$ XVIII ${ }^{\mathrm{e}}$ siècle. Le panorama exploratoire que nous proposons souhaite donc penser la citoyenneté avec le genre. Par là même, il entend proposer un bilan des enjeux historiographiques et historiques d'une question qui n'est pas nouvelle, mais qui peine encore beaucoup à se normaliser au sein la recherche française. Le plan thématique adopté invite à une réflexion par cas pratique, faisant varier les échelles d'analyse pour saisir l'implication des femmes dans la cité et ses modalités plurielles.

\section{Une histoire longtemps limitée au neutre masculin}

3 Le champ de l'histoire du genre, soit l'étude de la construction de la différence des sexes et l'analyse de la dimension sexuée du pouvoir, demeure en marge des grandes traditions historiographiques françaises ${ }^{3}$. Si elle a indéniablement gagné en visibilité ces dernières décennies, elle peine à exporter ses problématiques comme ses outils aux autres champs de la recherche historique, déclinés le plus souvent au neutre masculin, comme si ce neutre embrassait de manière impartiale la totalité de la vie humaine. De fait, l'histoire est longtemps restée « un métier d'hommes qui écrivent l'histoire des hommes, présentée comme universelle ${ }^{4}$.» Les visées critiques et féministes des études genre se heurtent en effet aux présupposés idéologiques qui ont organisé les cadres du discours historique à la fin du XIX ${ }^{e}$ siècle. Dans son ouvrage de référence paru en 1998, Écrire l'histoire des femmes et $d u$ genre, Françoise Thébaud rappelle ainsi que le prestige de cette discipline s'est construit en lien avec l'affirmation de la Nation et de la République, ainsi qu'avec l'exaltation des valeurs de la culture républicaine... Au premier rang desquelles trône l'universalité des droits 5 . Parce qu'ils déstabilisent un passé qui reste le garant de notre modèle démocratique contemporain, il est donc d'autant plus difficile de faire émerger des individus et des groupes non-inclus dans cet idéal. En outre, le poids du positivisme et sa revendication de s'en tenir aux seuls faits visibles du passé a longtemps maintenu «le fait des femmes » à l'écart du mouvement de l'histoire, en raison même de la particularité des modes de domination sexués: les jeux de pouvoirs dont elles font l'objet sont rarement explicites mais agissent souvent de manière souterraine en invisibilisant les minorités, comme l'explique Michèle Riot-Sarcey ${ }^{6}$. Il en va ainsi de la proclamation du suffrage dit « universel » sous la Révolution, dont la performativité du vocable occulte le référent masculin qui, en réalité, le définit. C'est bien pourquoi, poursuit Michèle RiotSarcey, dans une perspective de genre, « il importe de ne pas s'en tenir aux traces lisibles 
du passé qui privilégient le plus souvent le consentement, l'adhésion, voire la résistance collective, dans un ensemble de règles dont les présupposés restent dans l'ombre des énoncés ${ }^{7}$. " Le virilocentrisme implicite de la Révolution de papier a ainsi construit, pour les siècles à venir, les cadres d'une exclusion historiographique qu'il est possible de corriger, mais à condition d'exhumer d'autres discours et d'autres traces, moins visibles et moins instituées ${ }^{8}$.

De fait, la question de l'exclusion des femmes de la citoyenneté politique, parce qu'elle est demeurée en dehors des débats parlementaires, n'est que très rarement venue interroger les contours sexués de la citoyenneté dans l'histoire révolutionnaire. À l'occasion de son bilan historiographique sur « la citoyenneté politique au prisme du genre », Anne Verjus constate judicieusement que «ni Condorcet ni Guyomar, dont les textes servent aujourd'hui à rappeler qu'il existait bien à l'époque de la Révolution une pensée de l'égalité politique entre les sexes, n'ont prononcé leurs discours devant les députés9 ${ }^{9}$ » Il faut en effet attendre l'intervention du socialiste Pierre Leroux en séance publique à l'Assemblée (1851) pour que la possibilité d'accorder le droit de vote aux femmes soit officiellement débattue parmi les représentants du peuple ${ }^{10}$.

Du fait de ces silences de l'histoire, l'exclusion des femmes a pu alors être perçue par toute une histoire politique comme le résultat inconscient et mécanique des mentalités d'une société patriarcale ${ }^{11}$. En 1985, pour évacuer le problème de l'exclusion des femmes dans la cité révolutionnaire, Michel Vovelle argue du caractère irréaliste des revendications d'égalité politique: "Classons le rêve d'émancipation féminine au rang des anticipations, trop fortes sans doute pour prendre place dans cette aventure de dix ans. Il y a quelque naïveté à en conclure, comme l'ont fait certains auteurs féministes, au caractère foncièrement hypocrite d'un rêve de fraternité monopolisé par les hommes ${ }^{12}$. " Sans plus d'analyse sur les hiérarchies constitutives de la culture républicaine, les limites sexuées de la citoyenneté ont ainsi pu être légitimées sans que cette condition vienne contredire le principe d'une égalité entre « tous ».

6 Pourtant, par-delà ces voies traditionnelles de la discipline historique, l'histoire des femmes et les études de genre ont entrepris de déjouer la violence symbolique des silences de l'histoire et de la communauté des historiens pour « sortir des sentiers balisés des faits» afin d'accéder à l'invisibilité des divisions inégalitaires de la jeune cité républicaine ${ }^{13}$.

\section{Le tournant du Bicentenaire : participation, politisation et exclusion des femmes en Révolution}

7 L'approche de la célébration du Bicentenaire de la Révolution en 1989 déclenche une série de publications sur la citoyenneté des femmes, venant inaugurer un nouveau champ de recherche sur la période révolutionnaire ${ }^{14}$. Le tournant est palpable. Historiennes françaises et américaines entreprennent alors de sonder le droit de cité et l'expérience révolutionnaire de ces "citoyennes sans citoyenneté » selon la belle formule de Dominique Godineau, dont les travaux fondateurs sur les "Citoyennes Tricoteuses » (Alinéa, 1988) irriguent alors la réflexion sur la participation des femmes ordinaires à la vie de la cité ${ }^{15}$. Il s'agit donc à la fois de restituer l'histoire des femmes en Révolution, leur participation autant que leur politisation, et d'analyser cet oubli fondateur de la Révolution française qui, dans un même mouvement, proclame l'universalité des droits de l'être humain tout en excluant la moitié de la population de la citoyenneté16. Si les 
historiennes françaises, dans le sillage de l'histoire sociale marxiste, concentrent leurs études sur la politisation accrue des rapports sociaux et la richesse des actions féminines, soulignant ainsi l'horizon des possibles de la période révolutionnaire ${ }^{17}$, les historiennes américaines et les philosophes féministes bousculent quant à elles la consécration d'une vision libérale de la Révolution française ${ }^{18}$. Étudiant la construction du genre dans la culture politique révolutionnaire, ses répercussions sur la différenciation entre les sexes et la limitation du rôle des femmes dans la cité, ces historiennes concluent à l'avènement d'une « démocratie exclusive » reposant sur une communauté fraternelle de mâles égaux ${ }^{19}$. De telles divergences ne peuvent être réduites à un simple clivage franco-américain qui opposerait une culture de l'universel à une culture de la différence ${ }^{20}$, elles révèlent également la pertinence du questionnement féministe, dont l'intérêt durable tient à sa dimension critique et « à son refus de maintenir le statu quo ${ }^{21}$. "

8 L'historienne Dominique Godineau propose ainsi de mobiliser conjointement ces deux grilles de lecture afin de déployer une approche qui consiste à voir « comment fonctionne l'exclusion, et donc à repérer les tensions, les configurations particulières qu'elle produit nécessairement, ainsi que les moments où elle est remise en cause ${ }^{22}$.» Ainsi, l'exclusion politique des femmes construite par le discours comme par les institutions révolutionnaires n'est jamais absolue : elle comporte des failles que les individus peuvent parfois exploiter pour ménager des marges de manœuvres, de subversion et de revendication. En retour, l'analyse située des arts de faire féminins dans un contexte de révolution ne peut reposer que sur l'identification du système de contraintes dans lequel ces pratiques se déploient. Ces remarques visent alors à encourager la reprise des études sur les femmes et le genre en Révolution, qui connaissent un certain recul en France jusqu'au début des années 2000, le Bicentenaire ayant échoué à pérenniser ce terrain de recherche dans l'historiographie révolutionnaire. "Malgré des travaux connus, il est toujours nécessaire de justifier ce qui apparait comme un point de vue parmi d'autres, une "dimension" surajoutée » explique ainsi Jean-Clément Martin, un des rares historiens hommes en France qui s'est alors employé à promouvoir ce champ de recherche ${ }^{23}$. Les grands colloques historiographiques sur la Révolution française des années 2000 ont permis à cet égard de mener un combat discret, mais soutenu en faveur d'une approche sexuée du phénomène révolutionnaire ${ }^{24}$. En 2015, à lire la rubrique consacrée aux femmes et à la citoyenneté par les auteurs de la bibliographie "Citoyenneté, république, démocratie en France de 1789 à 1899 » d'Historiens-Géographes, il semble évident que le genre a gagné une réelle légitimité.

\section{Genre, famille et citoyenneté : les femmes, citoyennes paradoxales de la Révolution}

9 L'actuel « recentrement historiographique sur les frontières de la citoyenneté » a favorisé l'éclosion de nouvelles approches pour penser le genre de la Révolution ${ }^{25}$. Or la citoyenneté révolutionnaire est une citoyenneté par degrés, ce feuilletage se traduisant dans la division fondamentale constitutive du système représentatif entre citoyenneté active et citoyenneté passive. Ces degrés expliquent que plusieurs formes ou strates de citoyenneté puissent cohabiter au sein d'un même individu, en fonction de la place que celui-ci occupe dans la cité. Citoyennes passives, les femmes sont ainsi non pas exclues de la citoyenneté dans son ensemble, mais exclues de la citoyenneté politique et plus spécifiquement du droit de suffrage. Afin de qualifier cette subtile dégradation, Anne 
Verjus préfère la notion de "non-inclusion » à celle d'exclusion ${ }^{26}$. La place des femmes dans le système politique républicain est d'ailleurs fondée sur leur position subalterne dans la cellule familiale, unité élémentaire de la société révolutionnaire. "Citoyennes paradoxales ${ }^{27}$ », les femmes ont néanmoins la possibilité d'exploiter cette tension propre à leur droit de cité pour le renégocier : « le simple fait d'être appelées citoyennes n'est pas anodin » rappelle à ce titre Dominique Godineau ${ }^{28}$. Ainsi, notre travail a pu montrer que même les jeunes femmes pauvres pratiquant la prostitution, activité dépénalisée sous la Révolution, peuvent faire valoir leur identité de « citoyennes » auprès de l'administration révolutionnaire pour s'ériger contre l'arbitraire policier qui continue de les stigmatiser ${ }^{29}$. En octroyant aux femmes des droits civiques, la Révolution a de fait favorisé leur prise de parole et les a dotées d'un langage ainsi que de pratiques revendicatives spécifiques, qui permettent même aux plus dominées et aux plus exclues de la société de s'en emparer et d'agir.

En outre, il faut le rappeler, les combats menés par les femmes n'ont porté que marginalement sur le droit de suffrage. Celles-ci ont en général préféré investir les espaces publics subalternes, c'est-à-dire, pour reprendre la définition de Nancy Fraser, «des arènes discursives parallèles dans lesquelles les membres des groupes sociaux subordonnés élaborent et diffusent des contre-discours, ce qui leur permet de fournir leur propre interprétation de leurs identités, de leurs intérêts et de leurs besoins ${ }^{30}$. Des travaux de recherche récents ont ainsi montré l'importance de l'action politique des marchandes ou des institutrices qui, sans être nécessairement militantes révolutionnaires, mobilisent un langage et des pratiques politiques spécifiques pour faire valoir leur définition d'une citoyenneté au féminin, que celle-ci soit économique ou pédagogique ${ }^{31}$. Prises de parole publique ${ }^{32}$, littérature ${ }^{33}$, actions domestiques ${ }^{34}$ constituent donc autant de pratiques sociales qui sont politisées par les femmes au nom de leur citoyenneté.

Dans cette perspective d'une citoyenneté comprise dans un sens large, la famille a constitué un objet privilégié de la recherche pour penser l'articulation entre genre et politique durant la période révolutionnaire. Occupant une place centrale dans l'imaginaire politique de l'époque ${ }^{35}$, la famille est alors « la communauté "naturelle" qui distribue les droits électoraux des personnes à l'époque révolutionnaire ${ }^{36}$." Dans le courant des années 2000, les travaux d'Anne Verjus, Suzanne Desan et Jennifer Heuer ont permis de restituer la dimension sexuée du citoyen actif, chef de famille et «bon mari ». Ils ont aussi contribué à sonder la co-construction de la « sphère domestique ${ }^{37}$ » et de la sphère politique dans les années 1790 , refondant la famille comme une nécessité politique et non comme un objet naturel et antérieur à la construction de la sphère publique. Ils ont enfin mis en évidence la politisation des relations privées entre hommes et femmes ${ }^{38}$. En réformant la question du divorce, de l'égalité entre frères et sœurs face à l'héritage, des droits acquis par les enfants légitimes et les filles-mères, c'est en effet tout un pan des rapports entre les sexes qui se trouve transformé par les concepts de liberté individuelle et d'égalité civile. Pétitions, plaintes et actions intentées devant les tribunaux civils dévoilent une intense politisation du quotidien et permet d'apprécier comment les femmes s'emparent des réformes révolutionnaires au nom de conceptions diverses de la citoyenneté.

12 Ainsi, aux combats menés dans la rue, dans les clubs et à l'assemblée par les citoyennes militantes durant la Révolution, il faut adjoindre ces savoir-faire citoyens discrets, voire privés, qui s'expriment à la lisière de l'espace public et témoignent de l'horizon des 
possibles de ces citoyennes paradoxales. Réfléchir sur les formes de citoyenneté féminine pendant la période révolutionnaire, marquée par la transformation rapide et conflictuelle des normes et des pratiques les plus quotidiennes, c'est donc tenir un fil tendu entre les normes, les catégories assignées, les expériences vécues et les formes d'engagement des femmes, dans leurs diversités et contradictions, en dialectique constante avec celles des hommes.

\section{Une nouvelle politisation de la maternité}

Pensée et vécue comme une genèse politique, la Révolution se vit comme une crise anthropologique qui questionne la distribution sexuée des rôles sociaux. Si la protection et la reproduction de la communauté font depuis longtemps partie des principales fonctions assignées aux femmes, celles-ci se chargent, dans ce contexte inédit, de nouveaux enjeux politiques. Elles induisent aussi une tension cruciale : louées comme les mères d'un peuple qui met en scène sa propre naissance politique, les femmes sont en même temps enfermées dans un rôle ancillaire.

\section{Les fondements matrimoniaux de la communauté civique}

14 Avant même les prémices de la Révolution, certains courants des Lumières ambitionnent de conférer une dimension politique à la fonction maternelle dans la cité, promouvant les modèles de la «Mère éducatrice " (Madame de Genlis) ou même de la "Mère civique » (Jean-Jacques Rousseau) ${ }^{39}$. Répondant aux multiples peurs d'un déclin, d'une chute voire de la fin de la civilisation ou même de la parousie, ces projets imposent l'idée d'un retour aux origines, d'une "renaissance», au sens propre et figuré, dans laquelle les femmes tiendraient le rôle principal, un rôle présenté comme conforme à l'ordre naturel. Cette conception régénérative de la citoyenneté atteint son apogée pendant la fête du 10 août 1793, dite " de l'Unité », lorsque 86 vieillards venus de tous les départements sont invités à boire le lait qui s'écoule des seins de la statue d'Isis, trônant sur la fontaine de la Régénération, redonnant à ceux qui en ont besoin une nouvelle jeunesse.

Générer pour régénérer : la traditionnelle fonction procréatrice et nourricière du couple royal se reporte dès lors de plus en plus sur toutes les citoyennes ordinaires. Les mères qui allaitent sont célébrées ${ }^{40}$. En novembre 1790, au club féminin des «Dames patriotes » de Marseille, une certaine Marie Martin affirme que le lait maternel des femmes patriotes permet de transmettre aux enfants les principes d'égalité, l'amour de la patrie de la constitution $^{41}$. L'allaitement naturel est promu dans des dizaines de traités médicaux, la mère de famille étant invitée à nourrir et forger de nouvelles générations, un « homme nouveau » chargé d'énergie: "Femmes! Vous ne serez bonnes citoyennes que lorsque vous allaiterez vous-même vos enfants ! », lance M. Bacher dans son Journal de médecine en $1791^{42}$. Certaines femmes se plient à ces attentes, donnant publiquement le sein à leurs enfants, accomplissant un geste politique. La communauté civique qui s'invente après 1789 se reconnaît dans la métaphore de la "Mère patrie »: d'habitude, l'expression désigne souvent la France continentale au regard de l'empire colonial ${ }^{43}$, mais aussi la terre qui a fait naître la liberté, et dont les citoyens se considèrent comme les enfants. Dans ce contexte, les mères trouvent un rôle évident dans une société agencée selon le critère de l'« utilité » sociale : elles ont pour mission d'assurer la gestation, la naissance puis l'éducation d'une nouvelle génération de patriotes, la première génération du monde 
libre. Censés favoriser les «bonnes mœurs» de la communauté civile, le mariage et les naissances sont encouragés, alors que le célibat, en particulier celui des ecclésiastiques, est dénoncé comme anticivique. La lutte contre les habitudes aristocratiques inspire par conséquent une "politique de matrimonialisation » qui vise à donner une place centrale aux femmes ${ }^{44}$. Fondées sur des conceptions maternalistes malgré leur diversité, les politiques sociales des Assemblées révolutionnaires récompensent de ce fait prioritairement les mères de famille. L'encouragement à l'allaitement naturel s'accompagne d'une médicalisation et d'aides à l'accouchement. Avec les pauvres, les infirmes, les personnes âgées et les veuves, les femmes en couche et les mères constituent les principales bénéficiaires de la bienfaisance dès 1789. En mai 1790, un décret ordonne l'ouverture de nouveaux ateliers de filature pour les femmes, en particulier chargées d'enfants en bas âge, mais aussi pour les enfants ${ }^{45}$. Pendant la Convention nationale, entre 1793 et 1794, les femmes sont aussi les ayant-droits prioritaires de la politique de redistribution et de réduction des inégalités : le 11 mai 1794, le troisième titre du décret sur la Bienfaisance nationale vise à aider les mères et veuves ayant des enfants dans les campagnes ${ }^{46}$. Les jeunes femmes célibataires et sans enfants sont en revanche les oubliées de cette politique d'assistance ${ }^{47}$. La peur de la dépopulation ${ }^{48}$ et de la dégénérescence, présentes dès 1789 avec la peur du retour de l'Ancien régime, mais ravivées par la guerre et la guerre civile en 1793 , font de la fertilité révolutionnaire un leitmotiv obsédant. Après 1792 surtout, les républicains sont persuadés que la guerre politique qu'ils mènent aux royalistes et aussi une guerre démographique : en 1794 une estampe représente une allégorie féminine de la Vendée, «venant d'accoucher de 200.000 garçons ${ }^{49}$. " En 1795, Gracchus Babeuf accusera Robespierre et les Montagnards d'avoir expérimenté un "système de dépopulation " dans l'Ouest, reprenant une peur déjà exprimée dans les cahiers de doléances en 1789 : être un bon révolutionnaire, puis être un bon républicain, consiste à assurer la reproduction et la croissance de la nation. Ainsi, c'est en recourant aux clichés maternels que pendant l'été 1789, les « dames de Paris » tentent de protester contre la possible répression militaire : «Les femmes sont effrayées par l'appareil de la guerre et créées pour donner la vie ${ }^{50}$.»

Dans une fameuse allégorie de 1793, Louis-Simon Boizot exalte ainsi «La France républicaine, ouvrant son sein à tous les Français ${ }^{51}$. » Parce qu'elle est associée à cette fonction maternelle, la participation des femmes aux protestations alimentaires fait partie des habitudes de la révolte populaire ${ }^{52}$. Lieux importants de sociabilité politique, espaces de diffusion des informations, point de départ des mouvements collectifs, les marchés et les boulangeries sont les territoires de la politisation des femmes, qui sont plus nombreuses que les hommes dans $70 \%$ des troubles frumentaires observés ${ }^{53}$. Lors des journées d'octobre 1789, les femmes, emmenées par les dames de la Halle, brandissent des bouts de pain comme autant d'emblèmes politiques et réclament la régulation des prix « pour leurs enfants et les habitants de la ville.» Pendant la Révolution, les femmes interviennent ainsi régulièrement lors des crises alimentaires ou de flambée des prix (mouvements des 4 et 5 septembre 1793, du $1^{\mathrm{er}}$ avril 1795 et du 20 mai 1795). Exaltant cette fonction nourricière et matricielle, les fêtes, spectacles et cérémonies associent les femmes aux thèmes de la nature et du végétal: ce sont les femmes qui couronnent les citoyens avec des feuilles de laurier ou de chêne, qui portent les branches de peupliers lors des mobilisations collectives ou qui décorent les arbres de la liberté et veillent sur $e^{e u x^{54}}$. Placées au centre du cycle de la nature, les mères citoyennes se trouvent au cœur des fondements anthropologiques de la Révolution. Sur elles repose l'écrasante responsabilité de la survie des citoyens, mais surtout de la naissance d'un homme 
nouveau. Et comme les femmes se voient assigner le rôle de mères, garantes de la régénération de la nation, elles sont invitées à se conformer aux stéréotypes usuellement associés aux femmes. Ainsi, le soin et l'attention comptent parmi les premières capacités que l'on attend d'elles.

\section{Le soin et l'attention, qualités civiques féminines?}

Comme pour les mères spartiates, dont le modèle, largement remanié, est souvent cité, le dévouement et l'oubli de soi sont loués comme des actes de civisme maternel. Sacrifier sa famille, du moins accepter les privations domestiques, se résoudre au départ et à la mort des fils, des frères et des maris, est la plus grande vertu que l'on prête aux femmes patriotes, dont on attend qu'elles mobilisent toute leur "maison" pour la cause révolutionnaire. Surtout à partir de la guerre (20 avril 1792), les stéréotypes de la mère dévouée se multiplient, à commencer par les nombreuses images de veuves éplorées ou d'épouses faisant leurs adieux à leur mari volontaire. Dans le camp opposé, beaucoup de femmes s'engagent dans la Contre-Révolution car elles s'estiment gardiennes des propriétés familiales ou refusent le départ des hommes de leur famille, comme lors de la levée des 300000 hommes en mars 1793. Pour bien des femmes, la famille et la nation ne sont donc que deux échelles différentes mais liées du corps social, rendant impossible une distinction nette entre " sphère publique » et « sphère privée ».

«Bien diriger sa famille, élever ses enfants, porter secours à ses voisins ${ }^{55} »$ : présentée comme une des pionnières du féminisme, la britannique Mary Wollstonecraft assigne aux femmes une fonction qui peut pourtant sembler bien peu novatrice. Regardées comme les ultimes garantes de la cohésion des communautés, les femmes doivent plus que jamais prêter attention aux autres : les nourrir, les protéger, les soigner, les surveiller. Ainsi, ce sont d'abord elles qui se chargent de pleurer les morts. Ancienne, cette fonction funèbre fonde néanmoins le nouveau dolorisme politique qui cimente, dès le début de la Révolution, la nouvelle communauté civique, dans le sang des victimes. En juillet 1789, les veuves de ceux qui sont morts au siège de la Bastille organisent des funérailles publiques ${ }^{56}$ . Quatre ans plus tard, pendant l'été 1793, le cadavre de Marat est veillé puis enterré par les Citoyennes Républicaines Révolutionnaires, qui conservent ensuite son cœur comme une précieuse relique politique ${ }^{57}$. Lors des exécutions, ce sont plus souvent des femmes qui s'empressent de tremper des tissus dans le sang qui s'écoule de l'échafaud ${ }^{58}$.

Porte-paroles des douleurs collectives, les femmes sont aussi chargées de panser les plaies de ceux qui souffrent. De fait, le soin aux malades, aux blessés et aux démunis constitue une des premières formes d'engagement civique féminin, surtout à l'échelle locale : dans les communes et les cantons, les religieuses ou anciennes religieuses, mais aussi des domestiques ou des veuves s'activent dans les hôpitaux, les comités de bienfaisance, les sociétés politiques ou les agences de secours. Les plus croyantes vivent cet engagement comme un acte de charité, les autres comme un acte de bienfaisance voire, ce qui est plus nouveau, de solidarité avec ceux qui se battent pour défendre la Révolution puis, après l'automne 1792, de la République. Peint en 1792 par Watteau de Lille, Le Départ du volontaire fixe sur la toile cet idéal de la femme éplorée, chargée du soutien moral aux soldats et de l'assistance à ceux qui restent ${ }^{59}$. L'hospitalité fait aussi partie de cette vision genrée. Les femmes qui hébergent les fédérés en 1790, en 1792 et 1793 se targuent publiquement d'accueillir les citoyens soldats et donc de participer à la réunion de la communauté civique masculine, sans pour autant perturber les conventions de genre. Ce 
sont aussi des jeunes femmes qui tiennent les premiers rôles dans les cérémonies organisées pour accueillir le roi, les nouveaux prêtres et évêques constitutionnels, les autorités constituées ou même les troupes, lorsque celles-ci entrent dans les villes. Proche de cette fonction, le soin aux malades et aux blessés est une activité très féminisée. Souvent assuré par d'anciennes religieuses, ce besoin, vital en période de guerre et de guerre civile, constitue très tôt pour les femmes une occasion de faire valoir leurs « capacités ». Dans le même ordre d'idées, la loi du 25 mai 1791 exige que les agences de secours soient cogérées à parité par un homme et une femme, tous deux nommés par l'administration municipale, introduisant une nouvelle forme de mixité.

Mais le soin, c'est aussi, pour les femmes, celui qui consiste à veiller, c'est-à-dire à protéger le territoire familier des incursions " étrangères ». Cette surveillance féminine vient de loin : bien avant 1789, les femmes étaient les oreilles, les bouches et les yeux des paroisses, des quartiers et des maisonnées ${ }^{60}$. Mais la Révolution renforce et politise ces habitudes: la guerre, la guerre civile et la Dictature de Salut public augmentent les mobilités, aiguisent la peur et les dangers quotidiens. De plus en plus d'individus recherchés se réfugient dans la discrétion ou la clandestinité: les ennemis de la Révolution peuvent se cacher jusque chez les voisins. Alors que les identités politiques et sociales se brouillent, malgré les tentatives pour imposer des signes extérieurs clairs comme la cocarde, l'acuité du regard et la vigilance peuvent donc sauver la vie. Particulièrement mobilisées dans l'exercice de la dénonciation et de la vigilance citoyenne, les femmes sont très actives au sein des comités de surveillance, créés au printemps 1793 : si elles ne peuvent en être membres, elles ne cessent d'y intervenir, plus que les hommes, transposant leurs compétences habituelles dans un contexte très nouveau de qui-vive ${ }^{61}$. Sujettes à plusieurs faisceaux d'identités et de capacités assignées, les femmes ne sont enfin presque jamais pensées comme des individus indépendants de la famille, ce qui les désaffilie en partie de l'ancien patriarcat, mais les confine en même temps aux marges de l'espace public citoyen.

\section{La famille, point de départ... et d'arrivée pour les femmes ?}

21 Et si la Révolution française s'était avant tout vécue comme un « roman familial »? A la fin du XVIII siècle, la nouvelle histoire collective que les révolutionnaires inventent progressivement se conforme en effet à un "modèle familial de la politique " reposant sur l'égalité entre frères plutôt que sur l'obéissance au père. Cette utopie bouscule les hiérarchies de genre et affecte le quotidien des femmes ${ }^{62}$. Filles d'hommes dont le pouvoir s'érode, responsables de l'éducation des enfants, protagonistes de couples de plus en plus considérés comme des lieux de réciprocité, pièces maîtresses de parentèles et de lignées dont elles sont chargées de défendre la cohésion et la pérennité, les femmes se voient assigner dans la cité une place aussi centrale qu'ambivalente, comme le montrent ces paroles prononcées au Cercle Social en 1791: «[J]e dirais aux peuples corrompus [...]: adressez-vous au sexe en apparence le plus faible. Confiez-lui le soin de la régénération des mœurs. [...] Vous les verrez bientôt devenir citoyennes, épouses et mères, et l'Etat leur devra une partie de sa prospérité et de sa puissance. [...] Cette question est pourtant très difficile à traiter. Il ne faut pas que l'estime et la déférence que mérite à tant de titres ce sexe si précieux à l'Etat nous fasse passer les bornes, en leur assignant les fonctions qu'elles doivent exercer dans la société63. » 

maison, la plupart des femmes ont nécessairement moins de temps que les hommes à consacrer à d'autres activités. Mais la famille n'est pas qu'une prison, elle constitue aussi le point de départ de l'émancipation: la plupart des femmes qui critiquent la société d'ordres le font en dénonçant les injustices de la famille bien avant $1789^{64}$. Répondant à ces demandes, ainsi qu'à celles des cadets, désavantagés par le droit d'aînesse, les législateurs s'attaquent aux bases juridiques de la domination patriarcale, jusqu'à poser les jalons d'une "démocratie domestique » à venir. En 1790, les lettres de cachet sont supprimées et les couvents fermés, qui permettaient aux pères et aux maris de faire enfermer les mauvais fils, les filles indignes ou les épouses adultères en dehors de tout jugement. La toute-puissance paternelle est ainsi clairement remise en cause. Le 20 septembre 1792, deux jours avant la proclamation de la République, le divorce est reconnu. La concomitance chronologique ne tient pas que du hasard: fondé sur l'utopie d'une société plus égale, le changement de régime vise en premier lieu la plus petite structure de reproduction des inégalités et des modes de domination interindividuels ${ }^{65}$. La libéralisation et la dévirilisation du droit familial transforme pour la première fois les femmes en citoyennes de plein droit civil. Le 7 mars 1793, les députés votent l'égalité successorale en ligne directe, l'étendent le 26 octobre 1793 en ligne collatérale, puis aux enfants naturels le 2 novembre 1793, série complétée par les lois des 26 octobre 1793 et 6 janvier 1794. Fondée à l'été 1789 de manière abstraite et générale par la Déclaration des droits de l'Homme et du citoyen, l'égalité civile se traduit donc dorénavant pour les femmes de manière plus concrète, au sein de la cellule de base du quotidien.

Cependant, si la famille constitue un sésame pour intégrer la société civile, c'est celle-là même qui empêche les femmes d'entrer dans la société politique. Les femmes ne sont ainsi mentionnées par la Constitution de 1791 que comme des épouses et des mères, après les « pères de famille » (Titre VII- article 8). Et même en avril 1793 lorsque le droit de vote des femmes est proposé, d'une manière d'ailleurs totalement isolée, par Jacques-Marie Rouzet, il ne destine en priorité aux mères de famille ou aux femmes mariées ${ }^{66}$. Même lorsque les femmes font preuve d'une apparente volonté d'émancipation, l'affiliation au cadre masculin subsiste souvent de manière indirecte : ainsi, la plupart des femmes qui suivent les armées accompagnent les hommes en tant qu'épouses, lavandières, cantinières, infirmières ou même prostituées ${ }^{67}$. Certaines de ces femmes, comme l'avait fait la fameuse Margaret Corbin pendant la Révolution américaine, peuvent ensuite prendre la place de leurs maris morts au combat: en matière militaire comme dans d'autres domaines, les femmes n'accèdent à l'autonomie que par défaut, pour remplir le vide laissé par l'absence ou la disparition d'un père ou d'un époux ${ }^{68}$. De la même manière, beaucoup de celles qui s'engagent dans les sociétés politiques ou même dans les comités de surveillance le font à la suite d'hommes de leur famille ou de leurs employeurs, par imitation ou pour servir des stratégies familiales ou communautaires qu'elles défendaient autrefois au sein des confréries professionnelles, caritatives ou dévotes ${ }^{69}$. Enfin, la législation d'exception ne libère pas plus les femmes du joug familial et patriarcal que le droit ordinaire : après la loi des Suspects (17 septembre 1793), celles-ci peuvent en effet être condamnées pour des actions contre-révolutionnaires commises non par ellesmêmes, mais par des hommes de leur famille. En 1804, le Code civil propose un retour on ne peut plus clair à l'ordre indissociablement politique, social et patriarcal: selon l'article 213, «le mari doit protection à sa femme, la femme obéissance à son mari.» Mises sous tutelle, les femmes ne peuvent désormais gérer leurs biens et se voient 
davantage punies en cas d'adultère. En 1816, lorsque le divorce est supprimé, la famille redevient le lieu d'épanouissement de la domination masculine. Mais dans bien d'autres domaines encore, la Révolution tient les femmes aux confins de la société civile.

\section{Des citoyennetés subalternes}

\section{Les voies de l'exclusion des femmes}

Minorées et affiliées aux normes masculines, les femmes sont surtout, au quotidien, exclues des formes instituées de la participation politique. Sans être des «citoyennes passives ", elles ne jouissent ni des droits politiques que possèdent les citoyens actifs ni des marques de reconnaissance politique que les hommes se doivent de porter, comme si elles se trouvaient, en quelque sorte, un peu hors du jeu commun. Pourtant fondés sur une égalité de statut, les clubs mixtes, relativement rares (en 1794, ils ne totalisent pas $1 \%$ des clubs connus), ne comptent que moins d'un tiers de femmes et ne leur réservent qu'une place d'auxiliaires. Même dans l'avant-gardiste Société Fraternelle des Deux Sexes, le président est invariablement un homme. Toutefois, cette relégation s'accompagne d'une certaine intégration. Dans les tribunes des sociétés politiques, les femmes regardent, écoutent, discutent, applaudissent, huent ou interpellent les différentes orateurs ${ }^{70}$. Exclues des formes les plus actives de la vie citoyenne, les femmes sont en effet invitées à regarder et à participer au spectacle de la politique. Lors des fêtes, souvent choisies dans les familles des patriotes les plus en vue, elles sont invitées à s'asseoir au premier rang des tribunes, à poser les couronnes civiques, à porter des drapeaux ou des couronnes de fleurs, à défiler sous les traits de l'Egalité ou de la Liberté, à lire des textes ou à pleurer les martyrs.

Cette utilisation symbolique tient à la fois de la compensation et de la domestication : les femmes figurent au premier plan des mises en scènes de la Révolution, comme éléments vivants du décor. Actives lors des chantiers préparatifs aux fêtes de la Fédération à l'été 1790, elles sont surtout attendues comme spectatrices lorsque les festivités commencent réellement. "C'est au milieu des citoyens qu'on forme des citoyennes", affirme Euloge Schneider, le président des Jacobins de Strasbourg, le 24 décembre $1791^{71}$, défendant l'idée que c'est l'assistance aux pratiques politiques masculines qui permettra, un jour peut-être, aux femmes d'intégrer la communauté politique. Mais ce statut n'est pas qu'une relégation: comme spectatrices, ces femmes sont à la fois exclues et reconnues. Soulignée dans la presse, représentée et mise en scène sur les images, leur adhésion volontaire permet la naissance et la célébration de la collectivité civique, même si elles demeurent exclues de la pratique concrète de la politique. D'autres techniques de fidélisation et de neutralisation consistent à gratifier les plus modérées des femmes d'octobre 1789 d'une médaille en argent, gravées aux frais de la Commune et portant l'inscription de " bonne citoyenne ", aussi honorifique que vide de sens ${ }^{72}$.

Il faut dire que pour beaucoup, la Révolution prend le visage d'une possible confusion des sexes : jamais prouvées, les nombreuses rumeurs d'hommes déguisés en femmes lors des journées d'octobre 1789 distillent l'idée que les femmes sont manipulables et qu'elles dissimulent des « ennemis cachés ». Le répertoire souvent habituel utilisé par celles qui protestent est pourtant ressenti comme une subversion des équilibres anthropologiques. L'envahissement de l'Assemblée nationale, la violente mise en cause des députés, les insultes et les violences sont ressenties comme les effets mal contrôlés de la radicalisation 
politique des masses populaires sur les identités sexuelles. Pour certains, il devient vital d'endiguer de tels débords ${ }^{73}$.

Dès le 17 juin 1789, le député Duquesnoy condamnait déjà la présence des femmes dans les tribunes de l'Assemblée: "L'intérêt que prend le public aux discussions des Communes est vraiment inconcevable. Hier, plusieurs personnes ne sont pas sorties de la salle de toute la journée ; la cour, les vestibules sont remplis, et des femmes, jeunes, très belles, faites pour d'autres plaisirs, animent par leurs discours et leurs regards le patriotisme de ceux qui pourraient avoir besoin d'être excités par autre chose que par l'importance de l'objet ${ }^{74}$. » Trois ans plus tard, le rejet est encore plus sévère. Publiée vers le printemps 1793, une brochure anonyme propose une Nouvelle proclamation pour lever et enrôler dans toute l'étendue de la République, 300.000 filles et femmes pour aller aux frontières, depuis l'âge de 16 ans. Dédié à Bellone, la déesse de la guerre, ce pamphlet raille les prétentions des « filles qui attendent avec impatience le bonheur de partager la gloire de leurs chers amants ${ }^{75}$. " Tout au long de la Révolution, l'hypersexualisation des femmes les vide de raison politique. Le 17 novembre 1793, plus de quinze jours après la suppression des clubs féminins, Gaspard Chaumette interpelle les militantes qui viennent de pénétrer dans la salle de la Commune de Paris: « depuis quand est-il décent de voir des femmes abandonner le soin pieux de leur ménage, le berceau de leur enfant, pour venir sur la place publique, dans la tribune aux harangues, à la barre du sénat, dans les files de nos armées, remplir leurs devoirs que la nature a départis aux hommes seuls ?76.»

Surtout après 1794, les hommes insistent sur la "délicatesse » et la "sensibilité » féminines, qui incitent à les "préserver » des chocs du monde extérieur ${ }^{77}$. En 1799, ces convictions semblent plus établies que jamais: dans la comédie Les femmes politiques d'Étienne Gosse, une épouse, jugée coupable de s'être détournée de son ménage pour s'instruire des affaires politiques, est victime d'un simulacre d'arrestation au nom du principe que le « sexe [...] doit manier l'aiguille et non la plume ${ }^{78}$.»

29 En partie fondée sur ces stéréotypes, l'exclusion légale des femmes suit le tempo des crises politiques, culminant à partir de la guerre civile (fin 1792-début 1793) et se fixant sous le Directoire, avant de redevenir la norme indiscutée après 1804. Dès l'été 1789 , le vote des femmes s'était affirmé comme l'impensé des débats parlementaires. Les 14 et 22 décembre 1789, les lois instaurant le suffrage censitaire ne les mentionnent toujours pas, le genre masculin de la citoyenneté active demeurant une évidence implicite. Réaffirmée le $1^{\mathrm{er}}$ octobre 1789 et entérinée par la Constitution de 1791, la loi salique est même durcie par rapport à l'Ancien Régime, puisqu'elle exclut les femmes de la régence : la répulsion qu'inspirent Marie-Antoinette et les femmes de la Cour encourage une masculinisation du gouvernement ${ }^{79}$.

30 Alors que les demandes et projets de garde nationale féminine sont régulièrement ignorés et refusés dès 1790 , les partisans précoces de l'égalité des sexes, peu nombreux, se raréfient encore et certains font même marche arrière, surtout lorsque la guerre civile fait craindre une subversion de toutes les valeurs sociales. Après l'avoir demandée, Condorcet n'y fait plus aucune allusion dans le projet de Constitution qu'il présente les 15 et 16 février 1793. La mobilisation de la nation contre les ennemis du peuple s'accompagne d'un nouveau cloisonnement des identités sexuelles : le 30 avril 1793, les députés expulsent les femmes de l'armée ${ }^{80}$. Certes, certains députés se prononcent encore en faveur du droit de vote des femmes: c'est le cas du Girondin Guyomar ou du Montagnard Romme, dans son projet de constitution présenté le 17 avril 1793. Pourtant, ils sont complètement isolés. Six mois plus tard, le 30 octobre 1793 un décret visant 
surtout à abattre le militantisme radical interdit tous les clubs féminins. Impliquant de nombreuses femmes, les mouvements populaires du printemps $1795 \quad\left(1^{\mathrm{er}}\right.$ avril et 20 mai 1795, dits «journées de Prairial») incitent les députés à voter plusieurs décrets visant directement les femmes. Le 23 mai 1795, les hommes qui se sont travestis lors des émeutes du 20 mai ( $1^{\mathrm{er}}$ prairial an III) sont réprimés. Le lendemain, les députés privent les femmes de la possibilité d'assister à une assemblée politique, de pénétrer dans les tribunes de la Convention et de se rassembler dans la rue.

Dès l'automne 1789, mais surtout à partir de 1792, la multiplication des discours et la focalisation de la peur sur les femmes rendent celles-ci encore plus vulnérables aux violences. Dans certains cas, il est vrai que les clichés sur la faiblesse et la fragilité féminines encouragent certains hommes à les préserver. Ainsi, les femmes sont davantage épargnées que les hommes par la justice d'exception et échappent peut-être davantage aux violences de masse : lors des massacres de septembre 1792, «seulement " $8 \%$ des prisonnières sont tuées ${ }^{81}$. Pourtant, elles sont aussi très souvent prises pour cibles, les violences sexuelles s'ajoutant, en ce qui les concerne, aux autres types de violence ${ }^{82}$.

Le déshonneur frappant les femmes les dégrade en effet souvent à la fois sexuellement et civilement. Parce qu'elle dérégule les ajustements quotidiens du contrôle social et moral, la Révolution augmente probablement ces gestes. Les exemples sont légion. Le 8 juillet 1789, une noble est fessée en public pour avoir craché sur le portrait de Necker ${ }^{83}$. Après septembre 1792, le massacre de la princesse de Lamballe, perpétré comme un acte à la fois politique et sexuel, devient le symbole du martyre politique des femmes contrerévolutionnaires et de la toute-puissance de la virilité révolutionnaire ${ }^{84}$. Le 13 janvier 1795 (24 nivôse an III), des jeunes bourgeois fouettent des militantes présentes dans les tribunes de la Convention, arrachent leurs bonnets ainsi que leurs corsages : le geste est politique mais la violence est sexuelle ${ }^{85}$. Bien sûr, les femmes elles-mêmes peuvent recourir à de tels actes, à la fois parce que certaines adhèrent à la domination masculine, mais aussi parce qu'aux violences de genre se superposent des violences politiques et sociales : au printemps 1793, accusée de soutenir les Girondins, Théroigne de Méricourt est ainsi fessée devant les portes de la Convention par des militantes radicales. Elle en perdra la raison ${ }^{86}$. La violence de genre a aussi sa géographie, dont les points chauds se répartissent en fonction des tensions politiques et sociales. Les territoires les plus exposés à la guerre ou à la guerre civile voient ainsi se multiplier les violences sexuelles et sexuées. C'est le cas dans l'Ouest entre 1793 et 1795 surtout, les femmes des camps «Blanc» et «Bleu» étant, tour à tour, prises pour cibles ${ }^{87}$. Dans l'imaginaire républicain de la haine et de la peur, les femmes focalisent l'attention de manière disproportionnée, comme la princesse de Lamballe en septembre 1792 ou MarieAntoinette lors de son procès (16 octobre 1793). Symboliquement autopsiées ou mises en charpie, certaines femmes provoquent même de véritables obsessions : c'est le cas de Corday, l'assassin de Marat (13 juillet 1793), dont les mille et une figures, séduisantes ou monstrueuses, deviennent autant d'explorations de la différence sexuelle ${ }^{88}$.

\section{Entre différentialisme et utilité sociale : les répertoires de l'exclusion des femmes hors de la communauté politique}

Déjà utilisés depuis longtemps, différents types d'argumentaires sont utilisés par des hommes, mais pas seulement, pour justifier une telle différence. Ce que la Révolution 
change, c'est que ces justifications se radicalisent et se fixent au fur et à mesure de la place que les femmes prennent, à l'occasion de la Révolution, dans la vie publique. Cellesci sont qualifiées par une multitude de sobriquets dépréciatifs ("harangueuses», " poissardes ", «furies ", « mégères ", « jacoquines », " guenons ", « tigresses »), ou d'assignations genrées (« dames », « amazones », « filles »), alors que les injures visant les hommes relèvent de critères plus sociaux ou politiques... Sauf lorsque certains sont accusés de déviriliser la société et qu'ils sont traités de «femelles », de «femelettes » ou d'« hommasses ", surtout après 1792, lorsque la masculinisation de la citoyenneté dessine le stéréotype du sans-culotte viril et moustachu, identifié à sa pique ${ }^{89}$.

Contemporaine de la fabrique de la race, l'angoisse de la dénaturation masculine et de la dégénerescence sociale affecte profondément les catégories de genre. La multiplication des images pornographiques, des allusions scatologiques associées aux femmes (on pense aux nombreux écrits et images publiés lors de la fermeture des couvents, en 1790), montre que si le genre devient une arme du combat politique qui touche les hommes comme les femmes, il se fait davantage au détriment de ces dernières ${ }^{90}$.

La pensée de l'utilité sociale et des "capacités » leur fournit un premier recours: dans l'optique des libéraux, influencés par la pensée physiocratique, les femmes ne sont pas encore prêtes à construire activement la société politique, car encore trop dépendantes ${ }^{91}$. Ceux qui conditionnent le degré d'intégration politique à la plus ou moins grande utilité que jouent les individus au sein de la société, placent les hommes et surtout le paterfamilias au sommet de la hiérarchie des citoyens : «Il me paraît universellement reconnu, il l'est surtout en France, que les chefs de famille seuls sont citoyens [...] C'est en vertu de ce principe que les femmes, les mineurs, les domestiques, les soldats mêmes, sont exclus des droits de cité ", affirme Roederer en $1797^{92}$. Ces principes, il les professait dès 1788, dans son pamphlet De la députation aux Etats généraux, avec les mêmes arguments que ceux que formulait Sieyès dans Qu'est-ce que le Tiers Etat (1789). En 1795, Roederer précise encore sa pensée : "Je dis que pour être citoyen il faut avoir intérêt et moyen de servir l'Etat. [...] Je dis un intérêt direct, pour distinguer les femmes, les enfants, les domestiques, tout ce qui vit sous la domination et la protection de famille, et n'a qu'un intérêt éloigné à la prospérité publique ${ }^{93}$. » Talleyrand partage cette idée : l'exclusion des femmes des emplois et fonctions publics ne peut qu'augmenter le bien commun. Dépendantes et dominées, les femmes auraient à la fois moins d'intérêt personnel et de capacité que les hommes à prendre de bonnes décisions. Comme l'affirme Sieyès le 21 juillet 1789, « les femmes, du moins dans l'état actuel, les enfants, les étrangers, ceux encore qui ne contribueraient en rien à soutenir l'établissement public, ne doivent point influer activement sur la chose publique ${ }^{94} »$ : ce n'est, selon cette thèse, pas par principe ni à cause de la nature, mais en raison des différences d'utilité et d'éducation, que les femmes doivent être écartées des droits politiques tout en pouvant «jouir des avantages de la sociétées $»$.

Conscientes de ces discours, certaines femmes tentent d'ailleurs, au moins dans un premier temps, de s'émanciper des rapports de sujétion familiale et se focalisent sur l'accès à l'éducation, considéré comme un premier outil de libération. Cette conception utilitariste explique aussi pourquoi bien avant 1789 , les femmes peuvent avoir le droit de vote en l'absence des hommes, lorsqu'elles sont chefs de feux : dans certaines assemblées préparatoires aux Etats Généraux, elles rassemblent parfois près de $10 \%$ de la communauté électorale. Le genre disparaît alors derrière l'utilité économique et sociale, si bien que les veuves peuvent même être inscrites sous la catégorie d'« hommes » au sein 
des rôles fiscaux ${ }^{96}$. De la même manière, le 10 juin 1793, une loi précise que « le partage des biens communaux sera fait par tête d'habitant domicilié, de tout âge et de tout sexe ", en raison de la reconnaissance du rôle social des femmes à l'échelle des communautés ${ }^{97}$.

Peu s'opposent à ces arguments. Certes, Condorcet plaide en 1790 pour « l'admission des femmes au droit de cité ", déplorant que l'on ait « violé le principe de l'égalité des droits en privant tranquillement la moitié du genre humain de celui de concourir à la formation des lois ${ }^{98}$. » Mais de tels discours sont isolés et viennent souvent d'ailleurs. La défense de l'émancipation politique des femmes est en effet partiellement inspirée par celles et ceux qui médiatisent les débats britanniques en France, ou qui y ont eux-mêmes participé : dans son livre A Vindication of the Rights of Women (1791), traduit en Français en 1792, Mary Wollstonecraft tente d'inspirer une modification de la Constitution ${ }^{99}$. Le $1^{\text {er }}$ avril 1792, après avoir consacré ses premiers discours aux femmes battues, à l'abolition de la primogéniture, à l'égalité entre femmes et hommes en matière d'héritage et à la réforme du divorce, la Hollandaise Etta Palm plaide à l'Assemblée pour l'égalité entre femmes et hommes, en s'appuyant sur le droit naturel ${ }^{100}$. Aujourd'hui présentés comme les héros et pionniers d'un féminisme d'avant-garde, ces individus, comme Olympe de Gouges en 1791, parlent alors dans le désert. C'est pourquoi nous ne leur assignons, dans cet article, que la place qu'ils occupaient dans leur contexte : une place somme toute marginale.

D'autres argumentaires, plus puissants et déterministes, contribuent à cette marginalisation des femmes. En partie inspirés par la pensée du droit naturel ${ }^{101}$, ils justifient l'exclusion des femmes par une différence de nature entre les sexes, en s'appuyant sur les savoirs de certains médecins et naturalistes. Les théories du vitalisme font de l'énergie séminale masculine le moteur de la régénération sociale. Parallèlement, le succès de l'empirisme, en particulier du sensualisme, encourage une lecture différentialiste. Enfin, depuis les années 1750, un nouveau discours déploie des arguments plus moraux, faisant des femmes les sources de la décadence sociale : «les femmes nous rendent femmes ", écrit Rousseau en $1758^{102}$. Le rôle grandissant des femmes dans la vie publique et dans les cercles proches du pouvoir sont dénoncés: hypersexualisées, les femmes proches des cercles du pouvoir sont accusées d'user de leur séduction pour déviriliser les hommes et précipiter la société dans la déliquescence. Venant de traditions différentes, ces discours se croisent et posent les bases d'un différentialisme sexuel viriliste, fondé sur l'idée d'une mécanique propre aux femmes, qui nuirait à leur capacité citoyenne : plus réceptives aux stimuli de l'extérieur, plus soumises aux passions de l'âme et aux dérèglements du corps, les femmes seraient, par nature, moins stables et raisonnables ${ }^{103}$. Cette nature sensible et empathique des femmes leur permettrait en revanche de mieux éduquer et former aux bonnes mœurs, à condition que ces qualités s'exercent au sein de la sphère familiale et domestique ${ }^{104}$.

Mobilisant plusieurs types de discours scientifiques, ces théories imprègnent les discours politiques. Le 29 octobre 1793, la veille de la fermeture des clubs féminins et tout en fustigeant celles qui troquent leurs charmes contre "une pipe et une culotte", Chaumette invoque les «lois de la nature »: "Sois femme, les tendres soins sont dus à l'enfance, les détails du ménage, les douces inquiétudes de la maternité, voilà tes travaux ${ }^{105}$. " Le lendemain, à la Convention nationale, Amar présente son rapport au nom du Comité de sûreté Générale et enfonce le clou: «chaque sexe est appelé à un genre d'occupation qui lui est propre; son action est circonscrite dans ce cercle qu'il ne peut franchir ${ }^{106}$. " Traversés par les clichés sur les fureurs utérines et autres dérèglements féminins, les rapports de police se focalisent souvent sur la responsabilité des femmes 
dans les insurrections, en exagérant leur démesure et leur violence, légitimant une législation répressive ${ }^{107}$. Joué pour la première fois le 19 avril 1793, la pièce Les Femmes politiques de Demoustier rejette en dehors du genre les femmes qui se mêlent de «politiquer »: «Est-il rien de plus vain qu'une femme qui veut, en dépit du destin, se déféminiser! Cet être hétéroclite, du sexe qu'il usurpe et du sexe qu'il quitte, négligeant le solide et saisissant le faux, laisse les qualités et prend tous les défauts. Ces êtres-là ne sont d'aucun genre. Les femmes n'oseraient à leur ordre associer ces dames [...]. Leur rôle est celui de la neutralité108.» Dès 1789 , mais surtout sous le Directoire, le discours se médicalise encore, identifiant les écarts aux normes comme autant de pathologies: l'hermaphrodisme devient l'anomalie politique par excellence ${ }^{109}$. Assignées au non-genre, les femmes qui dérogent trop ostensiblement aux règles ne sont pourtant pas de simples «victimes » de la Révolution. Leurs actions aboutissent même parfois à l'acquisition de certains droits.

\section{Emancipations et engagements féminins}

\section{Une brèche juridique?}

Malgré les déceptions et certaines régressions, la Révolution transforme la place, la vision et d'abord le statut des femmes dans la société. Reconnues comme des membres de plein droit du souverain, les femmes sont, de fait, protégées par la Déclaration des droits de l'Homme et du citoyen et par la loi. La lutte contre les abus du patriarcat politique sur lequel repose la monarchie absolue passe par le déclin de la toute-puissance paternelle au sein de la cellule de base de la nation : la famille. La loi des 16 et 24 août 1790 interdit les lettres de cachet, supports de l'arbitraire des maris et des pères. A la même époque, l'Assemblée institue les tribunaux de famille, instances de médiation et d'arbitrage des conflits familiaux. Quant au Code pénal de 1791, il supprime l'obligation des femmes célibataires ou veuves à déclarer leur grossesse sous peine de mort et dépénalise l'homosexualité.

41 Ainsi, une partie du droit issu de la Révolution fait des femmes des individus majeurs et émancipés. Jadis sous tutelle filiale puis conjugale, elles deviennent indépendantes à 21 ans, âge de la majorité. Dotées d'une pleine capacité juridique, les femmes peuvent pour la première fois signer des contrats, entrer en justice, se marier sans autorisation parentale et agir sans accord d'un homme. Alors que dans bien des coutumes provinciales, les filles étaient pratiquement exclues des héritages, les différentes lois sur les successions ( 8 avril 1791, 7 mars 1793 et 6 janvier 1794) rendent tous les enfants des héritiers égaux) les placent à égalité avec les fils. Ces mesures transforment totalement la vie quotidienne de millions d'entre elles, même si les habitudes résistent parfois. Devenu un acte contractuel et civil, le mariage invente le couple comme un lieu de réciprocité : le " conjugalisme » devient l'idéal de la relation entre époux ${ }^{110}$. Le 8 août 1792, en partie au nom de l'émancipation individuelle, les communautés religieuses, représentées depuis longtemps comme de véritables prisons, sont supprimées. Le 28 août 1792, les pères perdent leur puissance juridique sur leurs fils, même après leur majorité (21 ans). Moins d'un un mois plus tard, le 20 septembre 1792, la loi sur le divorce est votée, reconnaissant les femmes comme les individus juridiques libres de dénouer le contrat conjugal. 
prévoit un enseignement gratuit et commun dans les écoles primaires et secondaires, jusqu'à 13 ans. Quant à Le Peletier, il imagine d'éduquer ensemble tous les enfants sans distinction de sexe dans son Plan d'éducation nationale, présenté le 13 juillet 1793. Le même Le Peletier soutient que les enfants doivent avant tout s'extirper de leur famille, qui, souvent, demeure un foyer de reproduction des inégalités et sujétions personnelles : dès 5 ans, les enfants doivent être envoyés dans des pensionnats républicains ${ }^{111}$.

Pour autant, ces divers projets ne visent à abolir les frontières de genre. Alors que les filles se voient enseigner la morale universelle, l'économie rurale et domestique (cours de couture, de filage et de blanchissement), les garçons doivent en plus apprendre les principes généraux de la Constitution. En décembre 1793, la République montagnarde affirme que la régénération ne peut venir que d'un programme d'éducation universel, gratuit et obligatoire pour les filles et garçons ${ }^{112}$. Le 19 décembre 1793 , les femmes peuvent aussi ouvrir des écoles : un an plus tard, elles forment à Paris ou à Marseille plus ou moins la moitié des enseignants ${ }^{113}$. Cela dit, les femmes ne font pas que « recevoir » de nouveaux droits. Elles agissent en permanence et, sans toujours nourrir de projet clair, contribuent à questionner les dominations établies, y compris masculines. Mais après l'été 1794, l'obligation et la gratuité scolaires sont supprimées. Les enfants des classes populaires et les filles se voient à nouveau écartés des projets d'éducation nationale. La formation d'instituteurs des deux sexes est remplacée par celle d'instituteurs exclusivement masculins. Convaincues que les filles doivent avant tout être éduquées pour devenir de bonnes épouses et de bonnes mères, les familles préfèrent les élever dans le cadre ordinaire de leur fonction civique et sociale : la maison. Quant aux institutrices que la République se proposait de former et de mobiliser pour la formation de l'esprit public, elles ne peuvent être que déçues : moins payées que les hommes, déconsidérées, elles sont cantonnées aux enseignements stéréotypés comme la couture, l'entretien du linge ou la surveillance des "bonnes moeurs ${ }^{114} »$. Considérée comme une chance pour beaucoup de femmes qui désiraient s'investir dans l'éducation des filles, cette profession demeure pensée comme le prolongement du rôle de mère de famille, qui reste d'ailleurs également un des principaux l'horizon des apprentissages, marqués par la couture et les travaux domestiques.

\section{Effractions citoyennes}

Parce qu'elle conduit de nombreux hommes à quitter au moins temporairement leurs foyers, la Révolution crée un « vide du pouvoir » masculin qui permet, de fait, à beaucoup de femmes de tenir des rôles qui, habituellement, leurs étaient interdits ou seulement concédés. C'est le cas des parentes de nobles et prêtres émigrés ou déportés, qui gèrent et défendent les propriétés, se démènent pour demander des pensions, réclamer une radiation sur la liste des émigrés, tromper la vigilance des autorités révolutionnaires ou les combattre ${ }^{115}$. Les femmes des députés font partie de celles qui sont concernées par le départ des hommes. Ainsi, pendant deux ans, du printemps 1789 au mois de septembre 1791, l'épouse du député Lepoutre se plaint de gérer seule et sans expérience l'exploitation familiale, située dans les Flandres ${ }^{116}$ : ce type de situation n'est pas toujours vécu comme une bonne nouvelle, mais comme une épreuve, qui peut néanmoins, par la force des choses, faire légèrement (et provisoirement) bouger les lignes. Contre les illusions romantiques d'un protoféminisme défendu par quelques héroïnes investies d'un programme déjà écrit, il faut prêter attention à ces millions de femmes ordinaires qui, dans la discrétion, réajustent les rapports de genre sans l'avoir souhaité ni prévu. 
D'ailleurs, comme dans la plupart des périodes d'incertitude et de crise politique, la grande majorité des femmes comme des hommes préfère le silence et l'attente à l'action spectaculaire. C'est ce que suggère l'exemple des religieuses, particulièrement frappées par la Révolution. Dans le diocèse de Poitiers, la moitié d'entre elles préfèrent la résistance passive à la rébellion contre la politique religieuse des Assemblées successives. Seule une minorité entre en résistance active et environ $10 \%$ d'entre elles seront emprisonnées pour activité contre-révolutionnaire ou comme parente d'émigrés. De la même manière celles qui quittent volontairement le couvent, sans attendre leur fermeture, n'atteignent pas $5 \%^{117}$. Aussi, il faut se rappeler qu'il n'existe a priori aucune unité politique des femmes : Olympe de Gouges dédie sa Déclaration (1791) à la reine mais critique les femmes les plus radicales. Quant aux dames de la Halle, souvent présentées de manière anachronique comme les fers de lance d'un féminisme conscient de lui-même et homogène, elles ne cessent, après les journées d'Octobre, de s'opposer aux militantes proches des sans-culottes et aux revendications féminines en général.

Pourtant, une partie des femmes passe à l'action politique pendant la Révolution, jouant un rôle parfois important, provoquant des débats parfois animés. Plus fréquente parmi les femmes du monde ouvrier, de l'artisanat, de la boutique, de la paysannerie aisée, mais aussi de la noblesse, vigoureuse dans les villes soumises aux tensions économiques et alimentaires, endémique dans les régions frontalières ${ }^{118}$, cette action féminine recoupe en grande partie celle des hommes, mais pas toujours : ainsi, la plupart des militantes des clubs féminins sont jeunes et âgées, alors que leurs alter egos masculins, dont les contraintes familiales sont plus faibles, ont souvent entre 30 et 40 ans ${ }^{119}$.

Les protestations économiques et sociales constituent le cœur de cet engagement féminin. Depuis de nombreuses décennies, les femmes figurent en tête des mouvements contre la suppression des communaux, contre la dérégulation du marché des produits de première nécessité, contre les abus seigneuriaux ou la pression fiscale ${ }^{120}$. Survenant dans un moment de crise alimentaire qu'elle aggrave par ailleurs, la Révolution renforce en outre le chômage féminin dans l'industrie textile, en essor depuis le traité de libreéchange de 1786, et pousse beaucoup d'entre elles à protester, avec les hommes, au nom du droit au travail et à l'assistance.

Or si la majeure partie de l'action féminine passe par le biais de pétitions, d'adresses et de prises de parole, la voie de la manifestation ou de l'insurrection est également possible. Alors que beaucoup de femmes se lancent dans les émeutes parisiennes contre la baisse des salaires ouvriers à la fin du mois d'avril 1789 (l'« affaire Réveillon»), de nombreuses ouvrières se mobilisent en Normandie et en Picardie contre l'introduction des machines anglaises $^{121}$. Les bris de machine de l'été 1789 sont en partie menés et organisés par des ouvrières, tout comme les protestations secouant les ateliers de filature ouverts pour les femmes nécessiteuses en 1790, 1791,1792, l'hiver 1793-1794 et le printemps suivant: protestant contre les bas salaires et les mauvaises conditions de travail, les ouvrières poussent même le directeur de la filature des Jacobins à la démission le 18 mars 1794 . L'assistance n'est pas la soumission, la politique de secours ne justifie pas l'exploitation, clament-elles, en substance.

S'il fonde l'indignation et l'action féminines, le terreau socio-économique contribue à la fabrique de la radicalité et pousse certaines femmes à repousser les barrières qui les confinaient jusque-là en marge de la communauté politique. L'action des femmes d'Octobre 1789 le montre bien : organisée dans un cadre très classique d'Ancien Régime, elle aboutit à une rupture aussi majeure qu'imprévue ${ }^{122}$. Sur le trajet de Versailles, ces 
femmes ne sont pas moins "politiques" ni moins radicales ni moins violentes que les hommes, même si cette violence est aussitôt exagérée, stéréotypée et dénoncée comme " contre-nature ${ }^{123} »:$ au son des slogans et des insultes contre la reine et son entourage, ces protestataires enfoncent les portes et détruisent leurs enseignes des commerçants qui, prévenus de leur arrivée, se cloîtrent et refusent de leur distribuer à manger ou à boire. Généralement minoré, le tempo les tensions de genre doit encore être réévalué pour mieux comprendre celui des secousses politiques. «Les hommes ont pris la Bastille royale, et les femmes ont pris la royauté elle-même ${ }^{124} »$ : saluée de manière un peu exagérée mais isolée par Michelet, mieux comprise par de nombreux travaux récents, l'importance des journées d'Octobre 1789 est généralement admise, sans être pleinement prise en compte dans les périodisations de la période révolutionnaire, alors qu'elles constituent une rupture au moins aussi forte que celles des journées de juillet.

Présentes dans les marches alimentaires qui mènent jusqu'aux lieux du pouvoir (comme dans les journées des 4 et 5 septembre 1793, du $1^{\text {er }}$ avril 1795 et du 20 mai 1795) les femmes participent ainsi à toutes les mobilisations collectives, depuis la journée grenobloise des Tuiles ( 7 juin 1788) jusqu'aux dernières insurrections radicales de 1795. Le font-elles d'une manière particulière? Il semble que les femmes se "spécialisent " effectivement dans certains modes d'intervention, en partie issus de leur rôle habituel: beaucoup de sources mentionnent leur rôle d'alerte. Ce sont souvent elles qui préviennent des dangers, qui sonnent le tocsin, crient, dénoncent publiquement les spéculateurs, appellent, mobilisent, encouragent les protestataires, interviennent lors des débats politiques, des procès ou des exécutions, haranguent ceux qui regardent les marches collectives ou menacent les passants récalcitrants. Peut-être plus souvent que les hommes, les femmes jouent en effet un rôle de vigilance de d'incitation à l'action, jouant de ce fait un rôle central dans la formation des collectifs politiques.

Celles et ceux qui décident de passer à l'action protestataire y sont souvent incités par des femmes dont l'intervention fait penser à l'existence d'un « protagonisme » de genre. Dans les journées d'avril et de mai 1795, ce sont également elles qui donnent le ton. Utilisant les stéréotypes, elles n'hésitent pas à ridiculiser publiquement le manque de courage et la faiblesse des hommes, haranguant ceux-ci afin de les faire réagir ${ }^{125}$. Bien souvent, elles interviennent également pour renouer les liens, dissuader la violence, pacifier les conflits : tout au long de la Révolution, de multiples violences sont ainsi évitées par l'intervention de femmes qui, plus que les hommes dans certaines situations, peuvent se permettre de jouer les conciliatrices : peint entre 1796 et 1799, le tableau Les Sabines de Jacques Louis David est une métaphore politique de cette fonction idéalisée des femmes dans la cohésion de la nation, l'apaisement des tensions et la réconciliation, en particulier après $1794^{126}$. D'ailleurs, la plupart du temps, les femmes révolutionnaires comme les contre-révolutionnaires participent de manière pacifique aux mouvements collectifs, souvent en famille ${ }^{127}$. Décrites de manière outrancière, les femmes ne sont en réalité ni particulièrement "agressives » ni particulièrement « douces ", mais se jettent dans des situations qui se présentent à elles, faisant de facto bouger les lignes.

Parmi les principaux lieux de l'engagement politique féminin, les clubs sont souvent cités. Si on excepte les clubs masculins où elles observent et interviennent indirectement, il existe au moins une trentaine de sociétés mixtes qui fonctionnent comme des zones de contact, de petits laboratoires de la fabrique du genre. On dénombre aussi une soixantaine de clubs de femmes qui peuvent fédérer plusieurs dizaines, voire centaines d'adhérentes (environ 400 à Dijon) ${ }^{128}$. Un club a plus particulièrement retenu l'attention. 
Le 10 mai 1793, la Société des Citoyennes Républicaines Révolutionnaires est fondée par Pauline Léon, Constance Evrard, Félicité Colombe et Claire Lacombe, bientôt riche d'environ 170 membres issues de la petite bourgeoisie marchande et artisanale, la domesticité ou le salariat. Si les membres du club ne réclament jamais l'égalité des sexes en public, elles refusent la domination masculine: dans une séance la citoyenne Monic affirme « les femmes sont dignes de gouverner, je dirais presque mieux que les hommes ${ }^{129}$ . \)

52 Les femmes assument parfois d'user de la force ou même de la violence. Alors que dès l'été 1789 , la capacité à prendre les armes est vue comme une compétence citoyenne de base, certaines femmes demandent le droit de participer à la défense de la patrie et au maintien de l'ordre public. Pendant le mouvement des Fédérations en 1790 à Marseille, la société des Dames héroïnes forme un bataillon ${ }^{130}$. En février 1792, la femme d'un artisan de Haguenau supplie les Jacobins de Strasbourg de la laisser combattre : «j'ai six enfants mais si la patrie est en danger, donnez-moi un fusil et une giberne et j'irai avec vous combattre les ennemis». Dans cette région frontalière, les femmes sont plus enclines à l'engagement militaire : en novembre 1792, plusieurs centaines de femmes écrivent une pétition dans le Courrier de Strasbourg ${ }^{131}$. Le 6 mars 1792, Pauline Léon présente à la Législative une pétition signée par 319 femmes qui demandent le droit d'organiser une garde nationale féminine au nom de la Déclaration des droits de l'Homme et du citoyen. En temps de guerre, de nombreuses femmes aident de toute manière à la résistance contre l'ennemi, comme lors du siège de Lille en septembre-octobre 1792 contre les Autrichiens ou de Lyon entre août et octobre $1793^{132}$, contre les troupes fidèles aux Montagnards. Dans les armées révolutionnaires, au moins une centaine de femmes est tolérée de fait, même après l'interdiction du printemps 1793 et certaines sont même régulièrement promues dans la hiérarchie militaire ${ }^{133}$. Ainsi, après avoir participé à la prise de la Bastille, la blanchisseuse Catherine Pochetat sert comme canonnière dans le bataillon de Saint-Denis, se vante d'avoir fait prisonnier un officier prussien. Blessée à Jemmapes puis à Aix la Chapelle, elle est même devenue sous-lieutenant et a commandé une compagnie de la légion des Ardennes à Liège ${ }^{134}$. Pourtant, ces réalités ne sont pas légalisées. Alors que le 26 mars 1793, dans la Société Fraternelle des Minimes, Théroigne de Méricourt en réitère la demande, début mai 1793, l'objectif du club des Républicaines Révolutionnaires est clair : former des compagnies d'amazones ", composées de toutes les femmes de 18 à 50 ans, chargées de " garder l'intérieur, tandis que leurs frères garderont les frontières ${ }^{135}$ . » Le 30 octobre 1793, l'offensive contre le mouvement sans-culotte sonne le glas de cet engagement féminin. Les clubs de femmes sont interdits, certains fermés manu militari au cri de «Vive la République ! A bas les [femmes] révolutionnaires ! ${ }^{136}$. »

Dans ce domaine comme dans d'autres, la Révolution s'avère en somme bien décevante: évident dans les faits, l'engagement des femmes dans le maintien de l'ordre et la défense armée ne sera jamais reconnu comme un droit. Cet écart entre les normes et les pratiques révèle les contradictions dans lesquels les révolutionnaires s'engagent dès l'été 1789 . Il rend nécessaire une investigation des mises en pratique de la citoyenneté pour apprécier, au-delà de l'horizon intellectuel, les incarnations concrètes de cette nouvelle identité. Régulièrement posée, la question de la place de la première des minorités politiques n'est pas entendue ou consciemment rejetée pour des raisons autant intellectuelles que politiques ou pragmatiques. S'il n'est pas possible de lire dans la Révolution française comme une « occasion manquée », tant l'occasion n'a en réalité jamais eu lieu, il est tout autant impossible de faire comme si l'évidence de l'exclusion n'avait pas été construite, 
ou qu'elle n'avait pas au moins un peu vacillé. La brèche demeure ouverte. Pendant la Révolution, le genre aura été un des lieux de contact, de transaction et de conflit qui, sans que cela n'« aboutisse » à une égalité de droit, vint néanmoins troubler les rapports entre les femmes et les hommes de la fin du XVIII ${ }^{\mathrm{e}}$ siècle et, par les paradoxes civiques dont il fut fécond, offrir un nouvel espace de revendications aux féminismes des siècles à venir.

\section{NOTES}

1. Joan W. Scott, « Genre : une catégorie utile d'analyse historique », Cahiers du GRIF, 1986-1988, no37-38, p. 151.

2. Le terme de "citoyennetés sociales » a été proposé pour éviter de restreindre la question aux seuls droits politiques : Pascale BARTHÉLÉMY, Violaine SÉBILlOTE, « Sous la citoyenneté, le genre », Clio, Femmes, genre, histoire, « Citoyennetés », 43/2016, p. 7-22.

3. Association nationale des études féministes, Le genre dans l'enseignement supérieur et la recherche, Paris, La Dispute, 2014.

4. Georges Duby, Michelle Perrot, Geneviève Fraisse (dir.), Histoire des femmes en Occident IV. Le XIXe siècle, Paris, Plon, 1991, p. 14.

5. Françoise THÉBAUD, Écrire l'histoire des femmes et du genre, Paris, ENS Editions, 1998, 228 p.

6. Michèle Riot-Sarcey, "L'historiographie française et le concept de "genre " ", Revue d'histoire moderne et contemporaine, 47-4, 2000, p. 805-814.

7. Ibid., p. 813.

8. Pauline moszkowski-OUARgLI, Citoyennes des champs. Les femmes de Beaumont-du-Périgord pendant la Révolution française, Rennes, PUR, 2015

9. Anne Verjus, La citoyenneté politique au prisme du genre. Droits et représentation des individus entre famille et classe de sexe (XVIIIe-XXIe siècles), Habilitation à diriger des recherches, Ecole Normale Supérieure de Paris, Paris, 2014, p. 19. Le mémoire d'habilitation peut être consulté intégralement en ligne. En lien avec la question de programme, nous recommandons particulièrement le bilan historiographique en introduction ainsi que la première partie consacrée à la famille comme unité politique : https://hal.archives-ouvertes.fr/ tel-00998659/document.

10. Le député réclame alors le droit de vote pour les femmes aux élections municipales.

11. Pierre Rosenvallon, Le sacre du citoyen. Histoire du suffrage universel en France, Paris, Gallimard, 1992; Patrice Gueniffey, Le nombre et la raison. La Révolution française et les élections, Paris, Editions. EHESS, 1993.

12. Michel Vovelle, La mentalité révolutionnaire: société et mentalités sous la Révolution française, Paris, Messidor, 1985, p. 285.

13. Michèle Riot-Sarcey, "L'historiographie française et le concept de « genre » »..., op. cit., p. 809.

14. Il faut cependant souligner les prémices de ces recherches en France dans le courant des années 1970. Paule-Marie Duhet, Les Femmes et la révolution 1789-1794, Paris, Gallimard, 1971 ; Louis Devance, «Le féminisme pendant la Révolution française », AHRF, 229-1, 1977, p. 341-376.

15. Dominique Godineau, « Autour du mot “citoyenne" ", Mots, 16-1, 1988, p. 91-110.

16. Seule manifestation internationale d'envergure consacrée aux femmes durant le Bicentenaire, le colloque de Toulouse offre une synthèse assez exhaustive de la multiplicité des 
pistes de recherche engagées dans l'histoire des femmes et du genre, Marie-France Brive (dir.), Les femmes et la Révolution française: actes du colloque international, 12-13-14 avril 1989, Université de Toulouse-Le Mirail, Toulouse, Presses universitaires du Mirail, 1989, vol. 3.

17. Dominique Godineau, Citoyennes tricoteuses: les femmes du peuple à Paris pendant la Révolution française, Paris, Perrin, 2004. Outre la publication de la thèse de Dominique Godineau sous la direction de Michel Vovelle, de nombreuses recherches sont impulsées dans les Université de Toulouse et d'Aix-Marseille, pionnières en matière d'histoire des femmes.

18. Sur ces controverses transatlantiques: Karen M. Offen, « The New Sexual Politics of French Revolutionary Historiography », French Historical Studies, 16-4, 1 octobre 1990, p. 909-922; Suzanne Desan, «What's after Political Culture? Recent French Revolutionary Historiography ", French Historical Studies, 23-1, 2000, p. 163-196 ; Dominique Godineau, « Histoire sociale, histoire culturelle, histoire politique : la question du droit de cité des femmes », dans Martine Lapied, Christine Peyrard (dir.), La Révolution française : au carrefour des recherches, Aix-en-Provence, Publications de l'Université de Provence, 2003, p. 293-302 ; Jacques Guilhaumou, Martine Lapied, «Les femmes et la Révolution française : recherches en cours", Revolution Française.net [En ligne]. URL: http://revolution-francaise.net/2006/08/26/67-les-femmes-et-la-revolutionfrancaise-recherches-en-cours.

19. Dorinda Outram, The Body and the French Revolution: sex, class and political culture, New Haven, Yale University Press, 1989; Joan B. Landes, Women and the public sphere in the age of the French Revolution, Ithaca, Cornell University Press, 1988; Geneviève Fraisse, Muse de la raison : démocratie et exclusion des femmes en France, Paris, Gallimard, 1995.

20. Interprétation que l'on retrouve notamment sous la plume de Mona Ozouf : Mona Ozouf, Les mots des femmes : essai sur la singularité française, Paris, Fayard, 1995.

21. Joan W. Scott, «Fantasmes du millénaire: le futur du " genre » au XXIe siècle », Clio. Femmes, Genre, Histoire, 32, 2010, p. 89-117.

22. Dominique GODINEAU, « Histoire sociale, histoire culturelle, histoire politique : la question du droit de cité des femmes ", dans Martine Lapied, Christine Peyrard (dir.), op. cit., p. 295.

23. Dominique Godineau, Lynn Hunt, Jean-Clément Martin, Anne Verjus, Martine Lapied, «Femmes, genre, révolution », AHRF, 358, octobre 2009, p. 143-166; Ce dernier publia ainsi une synthèse sur les femmes en révolution, Jean-Clément Martin, La Révolte brisée : femmes dans la Révolution française et l'Empire, Paris, Armand Colin, 2008; Clyde Plumauzille, «Déplacer le regard: la Révolution au prisme du genre ", dans Virginie Martin, Guillaume Mazeau (dir.), Mélanges en l'honneur de Jean-Clément Martin, Paris, Publications de la Sorbonne, à paraître.

24. L'histoire des femmes et du genre est ainsi présentée comme participant de l'extension du domaine de réflexion de la Révolution, Martine Lapied, Christine Peyrard (dir.), op. cit. ; JeanClément Martin (dir.), La Révolution à l'œuvre: perspectives actuelles dans l'histoire de la Révolution française, Rennes, PUR, 2005.

25. Voir l'article de Virginie Martin dans ce numéro, en particulier le passage sur les citoyennetés-limite: Virginie MARTIN, «La citoyenneté revisitée: bilans et perspectives historiographiques ", La Révolution française [En ligne], 9 | 2015. URL : http://lrf.revues.org/1370

26. Anne Verjus, Le bon mari: une histoire politique des hommes et des femmes à l'époque révolutionnaire, Paris, Fayard, 2010.

27. Joan W. Scott, La citoyenne paradoxale : les féministes françaises et les droits de l'homme, Paris, Albin Michel, 1998.

28. Dominique Godineau, «Histoire sociale, histoire culturelle, histoire politique : la question du droit de cité des femmes", dans Martine Lapied, Christine Peyrard et Michel Vovelle (dir.), op. cit., p. 296.

29. Clyde Plumauzille, Tolérer et Réprimer: prostituées, prostitution et droit de cité dans le Paris révolutionnaire (1789-1799), thèse de doctorat sous la direction de Pierre Serna, Université Paris 1 
Panthéon-Sorbonne, 2013 ; Clyde PLUMAUZILLE, Prostitution et Révolution. Les femmes publiques dans la cité républicaine (1789-1804), Seyssel, Champ Vallon, 2016, p. 349-369.

30. Nancy Fraser, Qu'est-ce que la justice sociale? reconnaissance et redistributio $\mathrm{n}$, Paris, La Découverte, 2005, p. 126.

31. Caroline FAyolLE, Genre, savoir et citoyenneté. Les enjeux politiques de l'éducation des filles (de 1789 aux années 1820), Thèse de doctorat sous la direction de Michèle Riot-Sarcey, Université Paris 8 , 2013 ; Katie JARVIS, Politics in the Marketplace: The Popular Activism and Cultural Representation of the Dames des Halles during the French Revolution, Thèse de doctorat sous la direction de Suzanne Desan, Wisconsin Madison, 2013.

32. Christine Fauré (dir.), « La prise de parole publique des femmes », AHRF, 344, juin 2006.

33. Carla Hesse, The Other Enlightenment: How French Women became Modern, Princeton, Princeton University Press, 2001.

34. Suzanne Desan, The Family on Trial in Revolutionary France, Berkeley, University of California Press, 2006.

35. Lynn A. Hunt, Le roman familial de la Révolution française, Paris, Albin Michel, 1995.

36. Anne Verjus, La citoyenneté politique au prisme du genre..., op. cit., p. 45.

37. Jennifer Heuer, Anne Verjus, "L'invention de la sphère domestique au sortir de la révolution ", AHRF, 327, mars 2002, p. 1-28.

38. Anne Verjus, Le cens de la famille: les femmes et le vote, 1789-1848, Paris, Belin, 2002; Jennifer N. Heuer, The family and the nation: gender and citizenship in revolutionary France, 1789-1830, Ithaca, Cornell University Press, 2005; Suzanne Desan, The Family on Trial in Revolutionary France..., op. cit.

39. Annie SMART, Citoyennes: Women and the Ideal of Citizenship in Eighteenth-Century France, Newark, University of Delaware Press, 2011, chap. 3.

40. Jean-Clément MARTIN, La révolte brisée..., op. cit., p. 89.

41. Laura talamante, Les Marseillaises: Women and Political Change during the French Revolution, Berkeley, University of California Press, 2003, p. 48.

42. M BACHER, Journal de médecine, de chirurgie et de pharmacie, Volume 89, octobre 1791, tome 89, p. 332.

43. Dictionnaire de l'Académie française, 1798.

44. Catherine DHAUSSY, Anne VERJUS, «De l'action féminine en période de révolte(s) et de révolution(s) », [en ligne] URL : http://dhaussy.verjus.free.fr/html/action.femmes.html

45. Elise KAMMERER, Les interventions des femmes dans l'espace public. Le cas du Bas-Rhin (1789-1795), Mémoire de Master 2 dirigé par Isabelle Laboulais, Université de Strasbourg., 2015, 202 p., p. 124.

46. Lisa DICAPRIO, The Origins of the Welfare State: Women, Work, and the French Revolution, Urbana and Chicago, University of Illinois Press, 2007, p. 100.

47. Clyde Plumauzille, Prostitution et Révolution. Les femmes publiques dans la cité républicaine (1789-1804), Seyssel, Champ Vallon, 2016, p. 29-69, p. 284-286.

48. Eric BRIAN, La mesure de l'Etat : administrateurs et géomètres au XVIII e siècle, Paris, Albin Michel, 1994, p. 272-278.

49. L.M., La Vendée venant d'accoucher de 200 mille garçons, leur papa Charette se prépare à les faire baptiser à Paris, Paris, 1794, BNF.

50. ANONYME, Lettre des dames de Paris, à messieurs les officiers du camp, 1789.

51. Louis-Simon воIzот (dess.), Alexandre CLÉMENT (grav.), La France républicaine, ouvrant son sein à tous les Français, estampe, 1793, BNF.

52. Arlette FARGE, «Évidentes émeutières », dans Natalie ZEMON DAVIS, Arlette FARGE (dir.), Histoire des femmes, vol. III, Paris, Plon, 2002 ; Dominique GODINEAU, Citoyennes tricoteuses, op. cit.

53. Jean NICOLAS, La rébellion française, Paris, Gallimard, 2002. 
54. Guillaume MAZEAU, « Paris, capitale des signes, vitrine de la Révolution (juillet-octobre 1789). Sémiologie politique des protestations collectives", dans Jean-Claude CARON (dir.), Paris l'insurrection capitale, Seyssel, Champ Vallon, 2015, p. 45-55; Mona Ozouf, La fête révolutionnaire, 1789-1799, Paris, Fayard, 1976, p. 426.

55. A Vindication of the Rights of Women, 1791, J. Stockdale, p. 189.

56. Joseph CLARKE, Commemorating the dead in Revolutionary France. Revolution and Remembrance, 1789-1799, Cambridge, Cambridge University Press, 2007.

57. Guillaume MAZEAU, Le Bain de l'histoire, Seyssel, Champ Vallon, 2009.

58. Jean-Clément MARTIN, «Le sang impur de la Révolution », Mentalités, 1988, 1, p. 111-123.

59. François Louis Joseph WATTEAU, Le départ du volontaire, huile sur toile, 73 x $59 \mathrm{~cm}, 1792$, Paris, Musée Carnavalet.

60. David GARRIOCH, Neighbourhood and Community in Paris 1740-1790, Cambridge, Cambridge University Press, 1986; Patrice HIGONNET, Goodness beyond Virtue, Jacobins during the French Revolution, Cambridge (Mass.), Harvard University Press, 1998.

61. Jacques Guilhaumou, Martine LAPIED, "Femmes et comités de surveillance ", dans Danièle Pingué, Jean-Paul Rothiot (dir.), Les comités de surveillance. D'une création citoyenne à une institution révolutionnaire, Paris, Société des Etudes Robespierristes, 2012, p. 125-131.

62. Lynn HUNT, The Family Romance of the French Revolution, Berkeley, University of California Press, 1992.

63. Discours au Cercle Social, La Bouche de fer, 6 janvier 1791, p. 29 et suivantes.

64. Susan DESAN, The Family on Trial in Revolutionary France, op. cit.

65. Jean-Jacques CLÉRÉ, «La Révolution française et la famille », dans Michel Biard (dir.), La Révolution française, une histoire toujours vivante, Paris, Tallandier, 2009, p. 287-302.

66. Jacques-Marie ROUZET, Projet de Constitution française, 18 avril 1793.

67. Jean-Clément MARTIN, « Travestissements, impostures et la communauté historienne », Politix, juin 2006, $\mathrm{n}^{\circ} 74, \mathrm{n}^{\circ} 2$, p. 31-48.

68. Catherine DHAUSSY, Anne VERJus, «De l'action féminine en période de révolte(s) et de révolution(s) ", , op. cit., [en ligne] URL : http://dhaussy.verjus.free.fr/html/action-femmes.html 69. Elise KAMMERER, op.cit.; Olivier CHRISTIN, Vox populi. Une histoire du vote avant le suffrage universel, Paris, 2013, Seuil, p. 92.

70. Dominique GODINEAU, «Surveiller la vertu politique ou tyranniser l'Assembler? Le rôle des tribunes politiques pendant la Révolution française », dans Michel BIARD, Philippe BOURDIN, Hervé LEUWERS, Alain TOURRET (dir.), Vertu et politique, Les pratiques des Législateurs (1789-2014), Rennes, PUR, 2015, p. 153-169.

71. Elise KAMMERER, op. cit., p. 91.

72. Haïm BURSTIN, Révolutionnaires, Pour une anthropologie de la Révolution française, Paris, Vendémiaire, 2013, p. 288.

73. Bronlislaw васZко, «Droits de l'homme, paroles de femmes, les journées des 5 et 6 octobre 1789 », dans Bronlislaw Baczko, Politiques de la Révolution française, Paris, Gallimard, 2008, p. 92-129.

74. Adrien DUQUESNOY. Un révolutionnaire malgré lui, Journal mai-octobre 1789, Paris, Mercure de France, 2016, n² 24, 17 juin 1789, p. 115.

75. Nouvelle proclamation pour lever et enroler dans toute l'étendue de la République, 300,000 filles et femmes, pour aller aux frontières, depuis l'âge de 16 ans, Paris, Provost, vers 1793.

76. Révolutions de Paris, $\mathrm{n}^{\circ}$ 216, 27 brumaire an II, t. XVII, p. 276.

77. David GARRIOCH, La fabrique du Paris révolutionnaire, Paris, La Découverte, 2012, chap. 1.

78. Etienne GOSSE, Les femmes politiques : comédie en trois actes et en vers, Paris, Hugelet, p. 47.

79. Geneviève FRAISSE, Muse de la Raison: démocratie et exclusion des femmes en France, Gallimard, Paris, 1989, p. 274. 
80. Thomas HIPPLER, "Service militaire et citoyenneté sous la Révolution française ", dans Raymonde MONNIER (dir.), Citoyens et citoyenneté sous la Révolution française, p. 271.

81. Jean-Clément MARTIN, Violence et Révolution, essai sur la naissance d'un mythe national, Paris, Le Seuil, 2012, p. 141.

82. Jean-Clément MARTIN, "Violences sexuelles, étude des archives, pratiques de l'histoire", Annales. Histoire, Sciences Sociales, 1996, vol. 51, nº 3, p. 643-661

83. ANONYME, Une femme de condition, fouettée pour avoir craché sur le portrait de Necker, estampe, Paris, 1789, BNF.

84. Antoine DE BAECQUE, La gloire et l'effroi. Sept morts sous la Terreur, Paris, Grasset, 1997.

85. Dominique GODINEAU, Citoyennes Tricoteuses, op. cit., p. 293.

86. Elisabeth ROUDINESCO, Théroigne de Méricourt, Une femme mélancolique sous la Révolution, Paris, Le Seuil, 1989.

87. Jean-Clément MARTIN, «Femmes et guerres civiles, l'exemple de la Vendée, 1793-1796 », Clio, Histoire, Femmes et Sociétés, 5, 1997, p. 97-115.

88. Guillaume MAZEAU, Corday contre Marat. Deux siècles d'images, Versailles, Artlys, 2009.

89. Haim BUSRTIN, L'Invention du sans-culotte, Paris, Odile Jacob, 2006.

90. Jean-Clément MARTIN, La Révolte brisée, op. cit., p. 76.

91. Pierre-Yves QUIVIGER, "Sieyès et Spinoza », dans Pierre-Yves Quiviger, Vincent Denis, Jean Salem (dir.), Figures de Sieyès, Paris, Publications de la Sorbonne, 2008, p. 233.

92. Pierre-Louis ROEDERER, «Réflexions sur l'ouvrage du citoyen Guiraudet, intitulé : De la famille, considérée comme l'élément des sociétés ", dans Journal d'Économie publique, 7 août 1797, dans Pierre-Louis Roederer, Oeuvres du Comte P.-L. Roederer,... Paris, Firmin-Didot, 1853-1859, vol.5, p. 98.

93. Cité par Catherine DHAUSSY, Anne VERJUS, art. cit., n. 46.

94. Préliminaire de la Constitution française, Paris, 1789, p. 37.

95. Ibidem.

96. Jean-Clément MARTIN, La Révolte brisée, op. cit., p. 132.

97. Collection Baudouin, vol. 38 (Juin 1793), p. 69.

98. CONDORCET, "Sur l'admission des femmes au droit de cité », Journal de la Société de 1789, 3 juillet 1790.

99. Sasha ROSENEIL (dir.), Beyond Citizenship? Feminism and the Transformation of Belonging, Basingstoke, Palgrave Macmillan, 2013, Sylvana TOMASELli (dir.), Cambridge University Press, 2009 (1 1 ère éd. 1995), p. 143.

100. Gary KATES, The Cercle Social, the Girondins and the French Revolution, Princeton, Princeton University Press, 1985, p. 122; AP, $1^{\mathrm{er}}$ avril 1792, p. 63.

101. Olwen HUFTON, Women and the Limits of Citizenship in the French Revolution, Toronto, University of Toronto Press, 1992, p. 4.

102. Jean-Jacques RouSSEAU, Lettre à d'Alembert sur les spectacles, Amsterdam, Marc, 1758 ; Thomas LAQUEUR, La fabrique du sexe. Essai sur le corps et le genre en Occident, Paris, Seuil, 1992 ; Danièle MAIRA, Jean-Marie ROULIN (dir.), Masculinités en révolution: de Rousseau à Balzac, Saint-Étienne, Publications de l'Université de Saint-Étienne, 2013.

103. Docteur тіssoт L'Onanisme, Lausanne, Marc Chapuis, 1760 ; Philippe HoffMAN, La femme dans la pensée des Lumières, Genève, Slatkine, 1995.

104. Yvonne KNIBIEHLER, «La «science médicale» au secours de la puissance mariale ", dans Christian BIET, Irène THÉRY (dir.), La Famille, la loi, l'Etat de la Révolution au Code Civil, Paris, Imprimerie nationale, 1989, p. 59-71.

105. Révolutions de Paris, $\mathrm{n}^{\circ} 216,27$ Brumaire an II, t. XVII, p. 276.

106. Moniteur Universel, 30 octobre 1793. 
107. Michel vovelLe, Religion et Révolution, Paris, Hachette, 1976, p. 252.

108. Charles Albert Demoustier, Les Femmes, Paris, Maradan, Acte 1, sc. VIII, p. 22.

109. Mechthild FEND, Les limites de la masculinité. L'androgynie dans l'art et la théorie de l'art (1750-1850), Paris, La Découverte, 2011.

110. Anne VERJUS, Le bon mari, op. cit.

111. Plan d'Education nationale de Michel Le Peletier présenté à la Convention par Maximillien Robespierre , Paris, de l'Imprimerie Nationale, 1793.

112. Caroline FAyOLLE, "Le sens de l'aiguille. Travaux domestiques, genre et citoyenneté (1789-1799) », Cahiers du Genre, 2012/2 (n 53), p. 165-187.

113. Caroline FAYOLLE, « Des institutrices républicaines (1793-1799) », AHRF [En ligne], 368 | avriljuin 2012, mis en ligne le 01 juin 2015. URL : http://ahrf.revues.org/12307

114. Ibid.

115. Guillaume MAZEAU, Le Bain de l'histoire, op. cit.

116. Jean-Pierre JESSENNE, Edna Hindie LEMAY, Député-paysan et fermière de Flandre en 1789. La correspondance des Lepoutre, Centre d'histoire de l'Europe du Nord-Ouest, Université de Lille, 1998. 117. Gwenael MURPHY, Les religieuses dans la Révolution française, Paris, Bayard, 2005.

118. Maxime KACI, A la croisée des politiques. Circulation des mots d'ordre et engagements collectifs à la frontière septentrionale (1791-1793), thèse de doctorat sous la direction d. Jean-Pierre Jessenne, Université Charles de Gaulle-Lille 3, dact., t. 1, 2012.

119. Dominique GODINEAU, Les Femmes dans la France moderne, op. cit.

120. Jean NICOLAS, La Rébellion française, Paris, Gallimard, 2002.

121. François JARRIGE, Au temps des «tueuses de bras». Les bris de machines à l'aube de l'ère industrielle (1780-1860), Rennes, PUR, 2009.

122. Katie JARVIS, "Allez, marchez, braves citoyennes»: A Study of the Popular Origins of, and the Political and Judicial Reactions to the October Days of the French Revolution, $\mathrm{PhD}$, Boston College University, 2007, dact., publiée chez BA, Boston College, 2007 et consultable ici:. http:// hdl.handle.net/2345/523.

123. Dominique GODINEAU, "Citoyennes, boutefeux et furies de guillotine ", dans Cécile DAUPHIN, Arlette fARge (dir.), De la violence des femmes, Paris, Albin Michel, 1997, p. 33-52 ; Jean-Clément MARTIN, «De la violence des femmes pendant la période révolutionnaire: un paradoxe persistant », dans Coline CARDI, Geneviève PRUvost (dir.), Penser la violence des femmes, Paris, la Découverte, 2012, chap. 3.

124. Jules MiCHELET, Les femmes de la Révolution, Paris, Delahays, 1855 ( $2^{\mathrm{e}}$ éd.), p. 26.

125. Dominique Godineau, Citoyennes Tricoteuses, op. cit.

126. Philippe BOURDIN, «Révolution française et conciliation », dans Jean-Claude Caron, Frédéric Chauvaud, Emmanuel Fureix, Jean-Noël Luc (dir.), Entre violence et conciliation. La résolution des conflits sociopolitiques au XIX ${ }^{e}$ siècle, Rennes, PUR, 2008, p. 23.

127. Micah ALPAUGH, Non-Violence and the French Revolution, Political Demonstrations in Paris, 17871795, Cambridge, Cambridge University Press, 2014.

128. Dominique GODINEAU, Les Femmes dans la France moderne, op. cit.

129. Suzanne DESAN, "Constitutionnal Amazons. Jacobin's Women's Clubs in the French Revolution", dans Bryant T. Ragan, Elizabeth A. Williams (dir.), Re-creating Authority in Revolutionnary France, Rutgers University Press, 1992, p. 11-35.

130. Thomas HIPPLER, "Service militaire et citoyenneté sous la Révolution française", dans Raymonde Monnier (dir.), Citoyens et citoyenneté sous la Révolution française, Paris, Publications de la société des Études robespierristes, coll. «Études révolutionnaires », 2006, p. 271-278.

131. Elise KAMMERER, Les interventions des femmes dans l'espace public..., op. cit., p. 32. 
132. Jean-Baptiste LESUEUR, Le Siège de Lille, gouache, vers 1794, Louvre, RF 36567 ; voir Maxime KACI, A la croisée des politiques. Circulation des mots d'ordre et engagements collectifs à la frontière septentrionale (1791-1793), op. cit., p. 356-357.

133. Jean-Clément MARTIN, La machine à fantasmes. Relire l'histoire de la Révolution française, Paris, Vendémiaire, 2012, "Tradition et transgression: les femmes soldats de la Révolution et de l'Empire », p. 137-161.

134. Christine FAURÉ, « Doléances, déclarations et pétitions, trois formes de la parole publique des femmes sous la Révolution", Annales historiques de la Révolution française [En ligne], 344 | avriljuin 2006, mis en ligne le 01 juin 2009, URL : http://ahrf.revues.org/5823.

135. Dominique GODINEAU, «De la guerrière à la citoyenne. Porter les armes pendant l'Ancien Régime et la Révolution française », Clio. Histoire, femmes et sociétés [En ligne], 20|2004, mis en ligne le 23 août 2013. URL : http://clio.revues.org/1418.

136. Claude GUILLON, "Pauline Léon, une républicaine révolutionnaire ", Annales historiques de la Révolution française [En ligne], 344 |avril-juin 2006, mis en ligne le 01 juin 2009, URL : http:// ahrf.revues.org/6213.

\section{RÉSUMÉS}

Pendant la Révolution française, le genre occupe une place centrale dans les recompositions de la société française, et en particulier dans les évolutions de la citoyenneté. Cet article vise à proposer un bilan des enjeux historiographiques et historiques d'une question qui n'est pas nouvelle, mais qui peine encore beaucoup à se normaliser au sein la recherche française. Il s'agit ici de montrer ce que les rapports de genre font aux différents types de citoyenneté et réciproquement. Cet article montre aussi comment cet oubli ou cette minoration de la question du genre dans l'histoire politique de la Révolution est préjudiciable à une bonne compréhension de la période dans toutes ses complexités. Le genre constitue en effet un laboratoire indispensable pour mieux saisir les rapports de domination à travers lesquels se sont vécues et réinventées les relations entre les femmes et les hommes de la dernière Révolution du XVIII ${ }^{\mathrm{e}}$ siècle.

The French Revolution challenged Gender identities and sexual representations, especially for what concerns the reconfigurations of citizenship. In this article, we would like to propose a summary of historiographical debates and issues on women's and gender history. More than twenty years after the Bicentenary controversies, it seems that Gender Studies have not yet become an ordinary field of research in France. We would like to show that this approach is central in the understanding of the political, social and anthropological crisis that broke out in France at the end of the XVIIIth Century, especially in what concerns new boundaries of citizenship.

\section{INDEX}

Mots-clés : Révolution française, historiographie, femmes, masculinité, genre, sexe, citoyennetés

Keywords : French Revolution, Historiography, Gender Studies, Citizenship, Masculinity, Women 


\section{AUTEURS}

\section{GUILLAUME MAZEAU}

Maître de conférences en histoire moderne, Université Paris-1, Centre d'Histoire du XIXe siècle mazeau.guillaume@free.fr

\section{CLYDE PLUMAUZILLE}

Post-doctorante de l'Institut Émilie du Châtelet au Centre de recherches historiques sous la direction de Sylvie Steinberg (EHESS), 2015-2017. 